\title{
Erythropoietin and IGF-1 signaling synchronize cell proliferation and maturation during erythropoiesis
}

\author{
Zahra Kadri, 1,2,6 Carine Lefevre, ${ }^{1,2,6}$ Olivier Goupille, ${ }^{1,2}$ Tipparat Penglong, 1,2,3 \\ Marine Granger-Locatelli, ${ }^{1,2}$ Suthat Fucharoen, ${ }^{3}$ Leila Maouche-Chretien, ${ }^{1,2,4}$ Philippe Leboulch, ${ }^{1,2,3,5}$ \\ and Stany Chretien ${ }^{1,2,4}$ \\ ${ }^{1}$ Commissariat à l'Energie Atomique et aux Énergies Alternatives, Institute of Emerging Diseases and Innovative Therapies \\ (iMETI), 92265 Fontenay-aux-Roses, France; ${ }^{2}$ UMR-E 007, Université Paris-Saclay, 91400 Orsay, France; ${ }^{3}$ Thalassemia Research \\ Center, Institute of Molecular Biosciences, Mahidol University, 73170 Nakhon Pathom, Thailand; ${ }^{4}$ Institut National de la Santé \\ et de la Recherche Médicale, 75013 Paris, France; ${ }^{5}$ Genetics Division, Department of Medicine, Brigham and Women's Hospital, \\ Harvard Medical School, Boston, Massachusetts 02215, USA
}

Tight coordination of cell proliferation and differentiation is central to red blood cell formation. Erythropoietin controls the proliferation and survival of red blood cell precursors, while variations in GATA-1/FOG-1 complex composition and concentrations drive their maturation. However, clear evidence of cross-talk between molecular pathways is lacking. Here, we show that erythropoietin activates AKT, which phosphorylates GATA-1 at Ser310, thereby increasing GATA-1 affinity for FOG-1. In turn, FOG-1 displaces pRb/E2F-2 from GATA-1, ultimately releasing free, proproliferative E2F-2. Mice bearing a Gata-1 ${ }^{S 310 A}$ mutation suffer from fatal anemia when a compensatory pathway for E2F-2 production involving insulin-like growth factor-1 (IGF-1) signaling is simultaneously abolished. In the context of the GATA-1 ${ }^{\text {V205G }}$ mutation resulting in lethal anemia, we show that the Ser310 cannot be phosphorylated and that constitutive phosphorylation at this position restores partial erythroid differentiation. This study sheds light on the GATA-1 pathways that synchronize cell proliferation and differentiation for tissue homeostasis.

[Keywords: GATA-1; IGF-1; signalization; differentiation; erythropoiesis; proliferation]

Supplemental material is available for this article.

Received June 18, 2015; revised version accepted November 12, 2015.

The production of red blood cells (RBCs) throughout life results from a differentiation process that generates more than 2 million reticulocytes every second in the bloodstream. The erythroid-specific transcription factor GATA-1 and its partner, FOG-1, play a central role in the cascade of gene activation and repression that results in the stepwise differentiation and maturation of RBC precursors (Patient and McGhee 2002; Crispino and Weiss 2014). Knockout of the erythroid transcription factor Gata-1 or its cofactor, Fog-1, leads to an arrest of erythroid development at the proerythroblast stage (Cantor and Orkin 2002). FOG-1 binds to GATA-1 and modulates its transcriptional activity at particular genes (Chlon and Crispino 2012). Several mutations that result in amino acid substitutions in the $\mathrm{N}$-terminal zinc finger of GATA-1 decrease or abolish FOG-1 binding to GATA-1 and are directly associated with hematological disorders. Affected patients display thrombocytopenia and/or ane-

${ }^{6}$ These authors contributed equally to this work.

Corresponding author: stany.chretien@cea.fr

Article is online at http://www.genesdev.org/cgi/doi/10.1101/gad.267633. 115 . mia with a severity proportional to the loss of affinity of GATA-1 for FOG-1 (Crispino 2005; Ciovacco et al. 2008; Chlon and Crispino 2012). For instance, the GATA-1 ${ }^{\text {V205G }}$ mutant, which is unable to associate with FOG-1, allows the initiation of erythroid differentiation up to the proerythroblast stage at which c-Kit is expressed; however, GATA-1 ${ }^{\mathrm{V} 205 \mathrm{G}}$ fails to repress c-Kit, to induce globin gene expression, and to initiate terminal erythroid differentiation in vitro or in vivo (Letting et al. 2004; Crispino 2005; Hong et al. 2005; Munugalavadla et al. 2005). Knockin mice that express GATA-1 ${ }^{\mathrm{V} 205 \mathrm{G}}$ fail to initiate terminal differentiation and die from anemia at embryonic day 11.5 (E11.5) (Crispino 2005). Association between GATA and FOG is thus crucial for the functions of these proteins, although the molecular mechanisms that regulate this association remain unknown.

Cell proliferation accompanies the various stages of cell differentiation in a tightly coordinated manner, and

(C) 2015 Kadri et al. This article is distributed exclusively by Cold Spring Harbor Laboratory Press for the first six months after the full-issue publication date (see http://genesdev.cshlp.org/site/misc/terms.xhtml). After six months, it is available under a Creative Commons License (Attribution-NonCommercial 4.0 International), as described at http:// creativecommons.org/licenses/by-nc/4.0/. 
erythroid cell proliferation and survival depend on stimulation of the erythropoietin (Epo) receptor (Epo-R) (Lacombe and Mayeux 1998; Tsiftsoglou et al. 2009; Kuhrt and Wojchowski 2015). GATA-1 exerts a repressive action on a subset of genes involved in cell proliferation (Rylski et al. 2003), and its overexpression inhibits cell proliferation (Dubart et al. 1996; Whyatt et al. 1997). This is partially explained by our previous finding that an LXCXE motif within the N-terminal region of GATA-1 is directly involved in the physical interaction between $\mathrm{pRb} / \mathrm{E} 2 \mathrm{~F}-2$ and GATA-1 (Kadri et al. 2009). Mice carrying a point mutation that disrupts the pRb-binding site of GATA-1 die of anemia in utero (Kadri et al. 2009). Sequestration of E2F-2 by the GATA-1/pRb complex results in cell cycle break at the G1/S transition, a crucial step for erythroid maturation (Kadri et al. 2009). In humans, several mutations in Gata-1, generating an N-terminally deleted GATA-1 protein (GATA-1s), have been described. GATA-1s is translated from a downstream ATG initiation codon that encodes Met ${ }^{84}$ in the full-length GATA-1. The association of GATA-1 with $\mathrm{pRb}$ is disrupted in GATA-1s because Met $^{84}$ is located within the LNCM $^{84}$ E-binding motif (Kadri et al. 2009). This type of mutation was first described in the transient myeloproliferative disorder and acute megakaryoblastic leukemia often observed in Down syndrome (Crispino 2005). It was later reported in patients with macrocytic or Diamond-Blackfan anemia (Hollanda et al. 2006; Sankaran et al. 2012; Parrella et al. 2014).

We also reported that the binding of FOG-1 to GATA-1 induces the dissociation of the GATA-1/pRb/E2F-2 complex, allowing the release of E2F-2 after phosphorylation of $\mathrm{pRb}$, which consequently abolishes the GATA-1-mediated inhibition of proliferation (Kadri et al. 2009). As the GATA-1 ${ }^{\text {V205G }}$ mutant cannot interact with FOG-1 (Letting et al. 2004; Crispino 2005; Hong et al. 2005; Munugalavadla et al. 2005), it is thus expected that pRb/E2F-2 and hence free E2F-2 remain abnormally sequestered despite the presence of FOG-1, providing a molecular basis for the inability of GATA-1 ${ }^{\mathrm{V} 205 \mathrm{G}}$ to initiate terminal differentiation and the fatal anemia observed in patients and mice bearing this Gata1 mutation.

It remains unclear how Epo signaling coordinates both erythroid differentiation and proliferation (Lacombe and Mayeux 1998; Tsiftsoglou et al. 2009; Kuhrt and Wojchowski 2015). Furthermore, little is known about "crosstalk" between the signal transduction pathways mediated by Epo-R and transcription factors, such as GATA-1 and FOG-1 (Patient and McGhee 2002; Crispino and Weiss 2014). In general, it is still unclear how the expansion of cell populations and differentiation processes are coordinated in various tissues. Post-translational modifications can link protein functions with cytokine signaling pathways and are crucial for the homeostatic regulation of tissues. Post-translational modifications of GATA-1 are required for the fine regulation of erythropoiesis; for example, lysine acetylation is necessary for the binding of GATA-1 to chromatin and erythroid differentiation (Lamonica et al. 2006). We and others have established a link between GATA-1 and the AKT signaling pathway and have shown that the phosphorylation of GATA-1 at Ser310 is required for erythroid differentiation in vitro (Kadri et al. 2005; Zhao et al. 2006). However, transgenic knock-in mice (Gata $1^{\text {tm9Sho})}$ expressing a mutated GATA-1 protein that cannot be phosphorylated (GATA$1^{\mathrm{S} 310 \mathrm{~A}}$ ) are viable and are not anemic (Rooke and Orkin 2006). This led us to reconsider the role of the GATA-1 phosphorylation mediated by Epo in both cell proliferation and differentiation.

We show here that the phosphorylation of GATA-1 on Ser310 is necessary for proper FOG-1 interaction and demonstrate its key role in normal and pathological erythropoiesis. We establish a novel pathway in which Epo-R stimulation activates AKT, which phosphorylates GATA-1 on Ser310; in turn, FOG-1 is then competent to associate with GATA-1pS310, thereby releasing $\mathrm{pRb} /$ E2F and, subsequently, free E2F-2, a final effector of cell proliferation. Finally, we reconcile previous discrepancies between in vitro and in vivo experiments by showing that Ser310 phosphorylation is essential in vivo, a fact that escaped previous investigators because another pathway in erythroid cells can compensate for the lack of release of E2F-2 from its sequestration by GATA- $1^{\text {S310A }}$. This pathway involves the compensatory production of E2F-2 by insulin-like growth factor-1 (IGF-1).

\section{Results}

Phosphorylation of GATA-1 at Ser310 by AKT enhances the association of GATA-1 with FOG-1

We first examined the phosphorylation status of GATA-1 in the human erythroleukemia cell line UT7 in the presence or absence of Epo (Fig. 1A). These experiments were carried out with an anti-human GATA-1 phosphoSer310 antibody (a-GATA-1pS310), whose specificity was first validated by Western blotting (Supplemental Fig. S1A-C). We found that $>90 \%$ of GATA-1 was phosphorylated at Ser310 in Epo-stimulated UT7 cells, whereas GATA-1pS310 was undetectable in Epo-starved cells (Fig. 1A). We carried out immunoprecipitation experiments with $\alpha$-GATA- 1 and $\alpha$-GATA-1pS310 antibodies, using an anti-human FOG-1 antibody for detection. This analysis indicated that FOG-1 bound only to GATA-1pS310 under these conditions (Fig. 1A). We then carried out "pull-down" experiments with oligonucleotides containing human GATA-1-binding sites in COS7 cells cotransfected with a mouse FOG-1 expression vector and a human GATA-1 mutant expression vector (either GATA-1 ${ }^{\mathrm{S} 310 \mathrm{~A}}$, which cannot be phosphorylated at Ser310, or GATA-1 ${ }^{\text {S310D }}$, which mimics constitutively phosphorylated Ser310). COS7 cells were also transfected with either a constitutively active AKT expression vector (myr-Akt) or a dominant-negative AKT expression vector (Akt-DN) to investigate the involvement of AKT in the association of GATA-1 with FOG-1. FOG-1 associated with constitutively phosphorylated GATA-1 (GATA$1^{\mathrm{S} 310 \mathrm{D}}$ ) and associated with wild-type GATA-1 only when Ser310 was phosphorylated by AKT (Supplemental Fig. S1D). These experiments confirm that AKT 
A

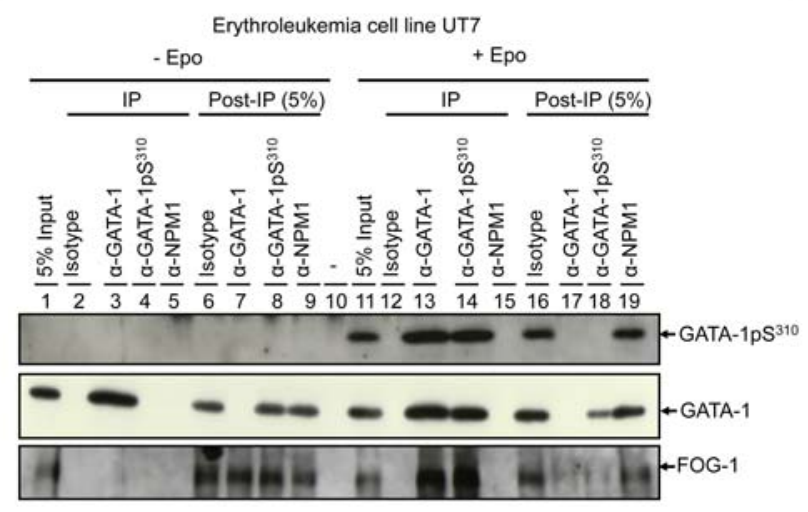

B

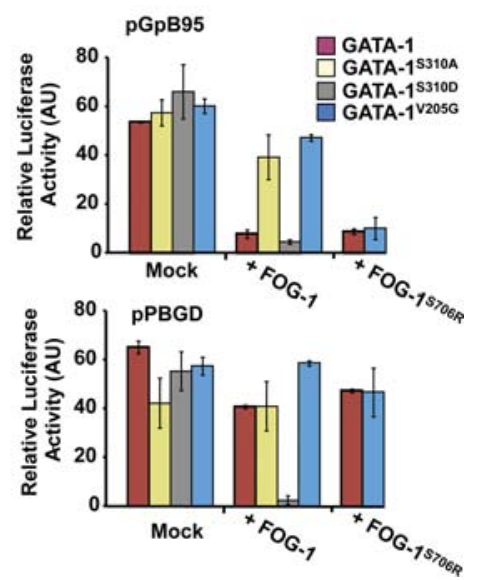

Figure 1. Phosphorylation of GATA-1 at Ser310 by AKT enhances the association of GATA-1 with FOG-1 and regulates transcription. (A) Immunoprecipitation and Western blotting to examine GATA-1/FOG-1 association in Epo-starved and Epo-stimulated UT7 cells. Immunoprecipitations were carried out on equal amounts of nuclear extract (500 $\mu \mathrm{g}$ per point). Specific antibodies ( $\alpha$-) that recognize GATA-1 phosphorylated at Ser310 (GATA-1pS310), GATA-1, or nucleophosmin (NPM1) proteins were used in immunoprecipitation experiments (IP), and 5\% of supernatants after immunoprecipitation (post-IP 5\%), as indicated, were subjected to Western blotting with a-GATA-1, a-GATA-1pS310, and $\alpha$-NPM1 antibodies. As a control, we also ran $5 \%$ of nuclear extracts before immunoprecipitation (5\% input) (see also the legend for Supplemental Figure S1). (B) Luciferase assays to analyze the effect of FOG-1 on the GATA-1-mediated transactivation of GATA-specific erythroid promoters (see also Supplemental Fig. S2): NIH-3T3 cells were transiently transfected with a luciferase reporter gene driven by the minimal erythroid-specific promoter of the glycophorin-B promoter ( $p G p B 95$ ) or the erythroid porphobilinogene deaminase promoter $(P P B G D$; nucleotides -714 to +78$)$, and cells were cotransfected with Migr-derived plasmids encoding GATA-1 or one of the GATA-1 mutants with and without FOG-1 or the FOG-1 ${ }^{\text {S706R }}$ variant that binds GATA-1 ${ }^{\text {V205G }}$ or GATA-1, as indicated. Error bars indicate the standard deviation from three independent experiments performed in triplicate.

phosphorylates GATA-1 at Ser310 and that this modification is required for FOG-1 binding to GATA-1.

\section{Inhibition of GATA-1-mediated transactivation of erythroid promoters by FOG-1 depends on GATA-1 phosphorylation at Ser310 in vitro}

We then assessed whether the association of FOG-1 with phosphorylated GATA-1 regulated transcription of erythroid promoters. FOG-1 is known to be required for erythroid differentiation/maturation in vivo, but its transcriptional activity in vitro is best assessed by scoring the paradoxical inhibitory effect of FOG-1 on the GATA-1mediated transactivation of minimum promoters bearing a GATA-1-binding site. We uncoupled pure GATA-1 transactivation or pure FOG-1 inhibition without interference from other erythroid factors or from the regulation of chromatin modifications by first cotransfecting nonerythroid NIH-3T3 cells with reporter constructs containing the luciferase gene driven by erythroid promoters together with GATA-1 or one of the various GATA-1 mutants to check that GATA-1 trans-activated erythroid promoters regardless of its Ser310 phosphorylation state (Supplemental Fig. S2A). We then carried out similar experiments in cells also transfected with the FOG-1 expression plasmid (Fig. 1B; Supplemental Fig. S2B-D). We observed two types of response in cells transfected with FOG-1 and wild-type GATA-1: FOG-1 strongly repressed the GATA-1-mediated transactivation of erythroid porphobilinogene deaminase promoter $(p P B G D)$ and the Epo- $R$ promoter $(p E p o-R)$, whereas FOG-1 poorly inhibited the
3XGATA-TK synthetic promoter (3xluc), the GATA-1 proximal promoter with its upstream enhancer element (pG1HE), and $p P B G D$ (Supplemental Fig. S2B). In cells expressing GATA-1 ${ }^{\mathrm{S} 310 \mathrm{~A}}$, FOG-1 did not inhibit $p G p B 95$ and $p E p o-R$, whereas FOG-1 transcriptional inhibition was restored in all cases in cells expressing GATA-1 ${ }^{\mathrm{S} 310 \mathrm{D}}$ (Fig. 1B; Supplemental Fig. S2C,D). Thus, FOG-1 inhibits the GATA-1-mediated transactivation of erythroid promoters in vitro when GATA-1 is phosphorylated at Ser310.

\section{A large excess of FOG-1 is required to free E2F-2}

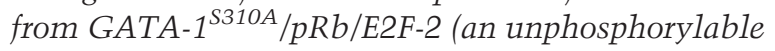
GATA-1 mutant)

We recently showed that GATA-1 inhibits cell division by sequestering the transcription factor E2F-2 (which is proproliferative in its free, nonsequestered form/ within a trimeric complex composed of GATA-1, pRb, and E2F-2 (Kadri et al. 2009). When FOG-1 is in excess, it associates with GATA-1 by displacing the other bound factors, thereby releasing E2F-2 (Kadri et al. 2009). Given the involvement of AKT in both cell cycle regulation and differentiation in vitro (Kadri et al. 2005; Zhao et al. 2006) and the ability of FOG-1 to alleviate the inhibitory effect of GATA-1 on cell proliferation (Kadri et al. 2009), we investigated whether the regulation of GATA-1/ FOG-1 association by AKT affects cell proliferation. We uncoupled proliferation from erythroid differentiation by first generating nonerythroid NIH-3T3 cells ectopically expressing GATA-1, GATA- ${ }^{\mathrm{S} 310 \mathrm{~A}}$, or GATA-1 ${ }^{\mathrm{S} 310 \mathrm{D}}$ by retroviral transduction. The three variants inhibited cell 
proliferation to a similar extent (Supplemental Fig. S3A). These cell lines were then transiently transfected with identical amounts of FOG-1 expression plasmid. Cell proliferation following FOG-1 transfection was correlated with the strength of GATA-1/FOG-1 complex formation: The percentage of proliferating cells was low in cells expressing GATA-1 ${ }^{\mathrm{S} 310 \mathrm{~A}}$, high in cells expressing GATA$1^{\mathrm{S} 310 \mathrm{D}}$, and intermediate in cells expressing wild-type GATA-1 (Supplemental Fig. S3A). We also transiently transfected NIH-3T3 cells expressing GATA-1 ${ }^{\text {S310A }}$ with increasing amounts of FOG-1 expression plasmid to assess whether GATA-1 ${ }^{\text {S310A }}$ and FOG-1 could associate at high concentrations of FOG-1. The growth of NIH-3T3 cells expressing GATA- ${ }^{\mathrm{S} 310 \mathrm{~A}}$ and the dissociation of $\mathrm{pRb} / \mathrm{E} 2 \mathrm{~F}-2$ from GATA- $1^{\mathrm{S} 310 \mathrm{~A}}$ were restored in the presence of a large excess of FOG-1 (Supplemental Fig. S3B,C). Quantitative analysis indicated that the overexpression of FOG-1 increased GATA- $1^{\mathrm{S} 310 \mathrm{~A}} / \mathrm{FOG}-1$ association. At ratio of 1 , no signal is observed when the GATA- $1^{\mathrm{S} 310 \mathrm{~A}}$ is expressed, whereas the GATA- ${ }^{\mathrm{S} 310 \mathrm{~A}}$ signal is maximal when FOG-1 is expressed at 50 -fold (saturating condition). We can estimate that the relative affinity of FOG-1 to GATA- ${ }^{\text {S310A }}$ is at least 25-fold less than the affinity of FOG-1 to wild-type GATA-1 (Supplemental Fig. S3C).

These in vitro studies suggest that the Epo/AKT-mediated phosphorylation of GATA-1 at Ser310 coordinates erythroid cell differentiation/maturation and proliferation by promoting the formation of the GATA-1/FOG-1 complex and the release of E2F-2 (Supplemental Fig. S4). Thus, the concentration of GATA-1/FOG-1 complexes is low in starved cells (AKT pathway inactive) or at times at which the abundance of FOG-1 is low or GATA-1 ${ }^{\text {S310A }}$ is expressed. Consequently, E2F-2 is sequestered within the GATA- $1 / \mathrm{pRb}$ complex, in which $\mathrm{pRb}$ is hypophosphorylated and the G1/S phase slows (Kadri et al. 2009), enabling differentiation to proceed (Supplemental Fig. S4A). Epo activates the AKT signaling pathway, which in turn induces GATA-1 phosphorylation at Ser310: The affinity of FOG-1 for GATA-1 increases and results in the dissociation of GATA-1 from pRb/E2F-2. After the subsequent phosphorylation of $\mathrm{pRb}, \mathrm{E} 2 \mathrm{~F}-2$ is released and reinitiates G1-to-S-phase progression, and a new GATA-1/FOG-1 equilibrium regulates transcription of the genes required for erythroid differentiation. Alternatively, a high abundance of nuclear FOG-1 can compensate for a low abundance of phosphorylated GATA-1 (Supplemental Fig. S4B). Thus, the transcriptional activities of GATA-1 and E2F-2 factors are inversely correlated and depend on both the activity of AKT kinase, which phosphorylates GATA-1 at Ser310, and that of the unknown phosphatase that dephosphorylates this residue. Thus, Epo drives the production of both the maturation complex GATA-1/FOG-1 and the proliferation factor E2F-2 in a synchronized manner (Supplemental Fig. S4C).

The Ser310 of the GATA-1 ${ }^{V 205 G}$ mutant fails to become phosphorylated after cytokine stimulation

Point mutations affecting GATA-1 amino acids between positions 205 and 218 interfere with the binding of
FOG-1. The severity of the anemia associated with these mutations is correlated with the degree of impairment of the FOG-1/GATA-1 interaction (Crispino 2005). Gata1 $^{\text {V205G }}$ knock-in mice display lethal anemia (Chang et al. 2002; Hasegawa et al. 2012), but the overexpression of GATA- ${ }^{\mathrm{V} 205 \mathrm{G}}$ in transgenic mice successfully rescues them from embryonic lethality (although they still suffer from severe anemia) (Hasegawa et al. 2012), indicating the partial reversibility of the lethal anemia of the GATA$1^{\text {V205G }}$ phenotype. In this particular model of Gata $1^{\text {tm9Sho }}$ knock-in, the mice are healthy (Rooke and Orkin 2006), but neither the GATA-1 ${ }^{\text {V205G }}$ nor the GATA-1 ${ }^{\text {S310A }}$ mutation can restore erythroid differentiation in vitro (Kadri et al. 2005; Zhao et al. 2006). We investigated whether the inability of FOG-1 to bind GATA- $1^{\mathrm{V} 205 \mathrm{G}}$ could be explained in part by an impairment of Ser310 phosphorylation. We thus examined the phosphorylation status of the GATA-1 ${ }^{\text {V205G }}$ mutant in NIH-3T3 cells and found that Ser310 was not phosphorylated after cytokine stimulation (Fig. 2A), suggesting that the inability of FOG-1 to bind GATA-1 $1^{\mathrm{V} 205 \mathrm{G}}$ may be partly due to the lack of phosphorylation at Ser310. Next, we investigated the relative affinities of different GATA-1 ${ }^{\mathrm{V} 205 \mathrm{G}}$ mutants for FOG-1 relative to that of the GATA- $1^{\mathrm{S} 310 \mathrm{~A}}$ mutant. For this comparison, we transduced NIH-3T3 cells expressing GATA$1^{\text {S310A }}$, GATA-1 ${ }^{\text {V205G }}$, GATA-1 ${ }^{\text {V205G-S310A, and GATA- }}$ $1^{\text {V205G'S310D }}$ (S-to-D 'mutation, mimicking constitutive phosphorylation at Ser310) mutant proteins with various amounts of FOG-1 vector. Protein-protein interactions were investigated by immunoprecipitation: As expected, GATA-1 ${ }^{\mathrm{V} 205 \mathrm{G}}$ and GATA-1 ${ }^{\mathrm{V} 205 \mathrm{G}-\mathrm{S} 310 \mathrm{~A}}$ mutants were unable to bind FOG-1 even at high FOG-1 concentrations, whereas GATA-1 ${ }^{\text {S310A }}$ and GATA-1 ${ }^{\text {V205G-S310D }}$ were able to bind FOG-1. At identical FOG-1 concentrations, the rate (62 vs. 29) of binding to FOG-1 was twofold higher for the GATA-1 ${ }^{\text {S310A }}$ mutant than for GATA-1 ${ }^{\text {V205G-S310D }}$ (Supplemental Fig. S5A). As the V205G mutant protein has an ectopic subcellular localization (Lee et al. 2009), we then studied the nuclear distribution of these GATA1 mutants. We investigated, by immunofluorescence and confocal microscopy analyses, whether Ser310 phosphorylation modified the subnuclear distribution of the GATA-1 $^{\text {V205G }}$ mutant (Supplemental Fig. S5B). A ringlike/diffuse distribution was observed in $81.5 \%$ of GATA-1 ${ }^{\text {V205G }}$-expressing cells, as previously described (Lee et al. 2009), and 87.6\% of GATA-1 ${ }^{\text {V205G-S310A }}$-expressing cells, whereas GATA-1 ${ }^{\text {S310A }}{ }_{-}$, GATA-1 ${ }^{\text {V205G-S310D }}{ }_{- \text {, }}$ and GATA- ${ }^{\mathrm{WT}}$-expressing cells displayed the same pattern (localization of GATA-1 to speckles), with a ringlike/diffuse distribution in only $15.7 \%, 15.5 \%$, and $11.6 \%$ of cells, respectively (Supplemental Fig. S5B). Constitutive phosphorylation of the GATA-1 ${ }^{\text {V205G }}$ mutant restored a partial FOG-1 binding and a subcellular distribution similar to that of GATA- ${ }^{\text {S310A }}$.

Mimicking constitutive Ser310 phosphorylation within GATA-1 $1^{\text {205G }}$ and high amounts of FOG-1 restore erythroid maturation

We sought to characterize further the roles of GATA-1 Ser310 phosphorylation and FOG-1 binding in erythroid 
A

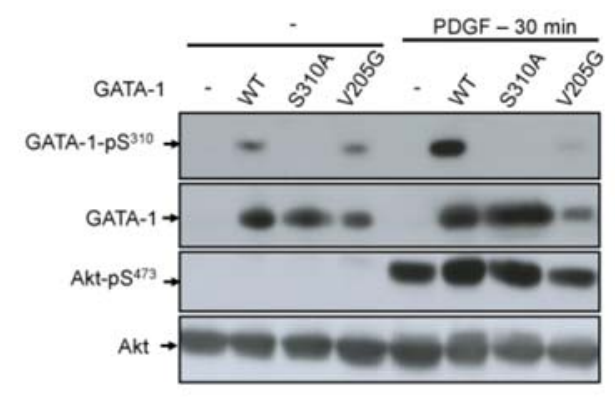

C

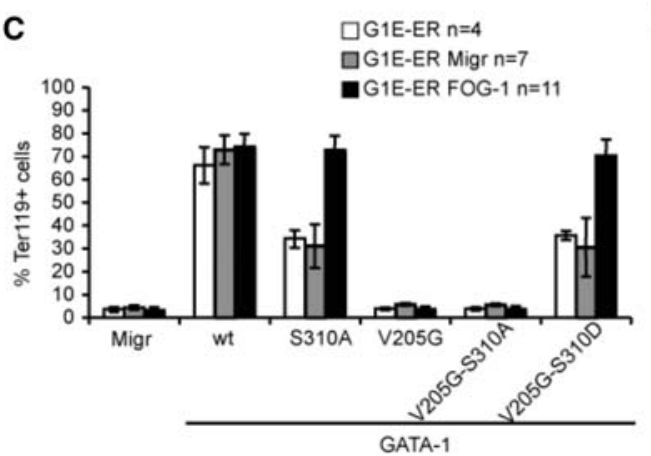

B

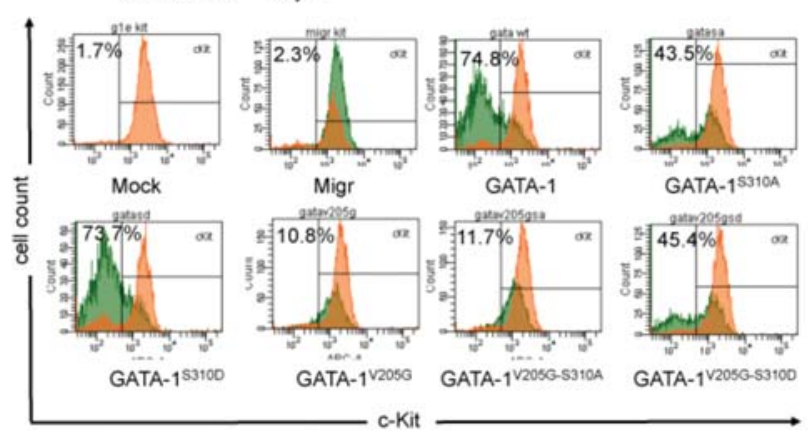

D

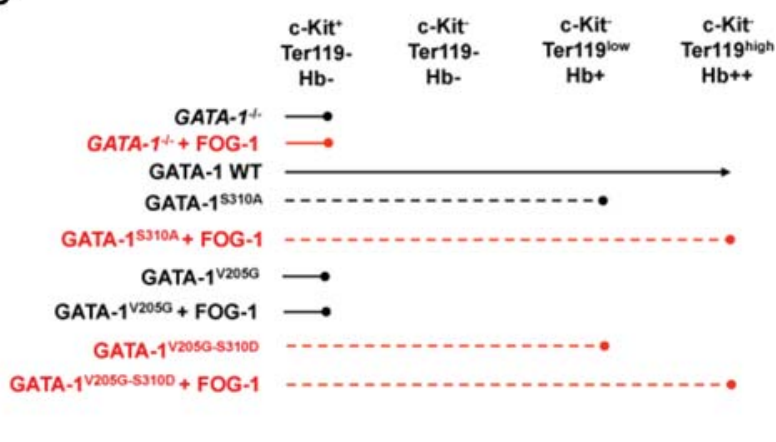

Figure 2. Constitutive phosphorylation of the GATA-1 ${ }^{\mathrm{V} 205 \mathrm{G}}$ mutant at Ser310 and high levels of FOG-1 restore erythroid maturation. (A) Western blot analysis showing GATA-1 ${ }^{\text {V205G }}$ Ser310 phosphorylation in NIH-3T3 cells transduced with the GATA-1 ${ }^{\text {V205G }}$ mutant and starved (-) or stimulated with PDGF. The GATA-1 ${ }^{\text {S310A }}$ mutant was used as nonphosphorylatable negative control. (B) Flow cytometry analysis of c-Kit expression in G1E cells transduced with an "empty" retroviral vector (Migr) or a vector encoding GATA-1 or one of the GATA-1 mutants, as indicated. The percentage of c-Kit-negative cells in the positive EGFP fraction is indicated. $(C)$ FACS analysis of Ter $119^{+}$cells to examine erythroid differentiation in G1E-ER (G1E expressing a GATA-1 construct fused to an estrogen receptor ligand-binding domain) cells transduced as in A. G1E-ER cells, G1E-ER cells transduced with Migr (G1E-ER Migr), and G1E-ER cells overexpressing FOG-1 (G1E-ER FOG-1) were transduced with a construct expressing GATA-1 or one of the GATA-1 mutants, as indicated. The results shown are means \pm SEM. $(D)$ Schematic representation of the erythroid differentiation capacity of each GATA- 1 mutant in the conditions used in this study.

differentiation. We therefore transduced Gata-1- G1E proerythroblast cells with retroviral vectors expressing wild-type GATA-1, GATA-1 ${ }^{\text {S310A }}$, GATA-1 ${ }^{\text {S310D }}$, or

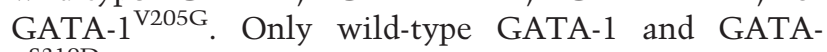
$1^{\mathrm{S} 310 \mathrm{D}}$ enabled proerythroblast cells to differentiate (Fig. 2B). However, GATA-1 ${ }^{\mathrm{S} 310 \mathrm{~A}}$ was able to inhibit c-kit expression, an early step in erythroid maturation, whereas GATA-1 ${ }^{\text {V205G }}$ was not (Fig. 2B). We then transduced Gata1- G1E proerythroblast cells with the GATA$1^{\mathrm{V} 205 \mathrm{G}-S 310 \mathrm{D}}$ double mutant. The production of either GATA-1 $1^{\mathrm{V} 205 \mathrm{G}-\mathrm{S} 310 \mathrm{D}}$ or GATA-1 ${ }^{\mathrm{S} 310 \mathrm{~A}}$ resulted in similar levels of inhibition of c-Kit expression (Fig. 2B). Thus, the constitutive phosphorylation of Ser310 in the GATA-1 ${ }^{\mathrm{V} 205 \mathrm{G}}$ led to the down-regulation of c-Kit expression during the early stage of proerythroblast differentiation, thereby partially restoring erythroid maturation.

We attempted to rescue erythroid differentiation in G1E-ER (G1E expressing a GATA-1 construct fused to an estrogen receptor ligand-binding domain) cells transduced with GATA-1 ${ }^{\mathrm{V} 205 \mathrm{G}-\mathrm{S} 310 \mathrm{D}}$ and GATA- ${ }^{\mathrm{S} 310 \mathrm{~A}}$. Previous reports have shown that alterations to the expression level of other GATA factors can rescue the lethal phenotype of Gata1 knockout mice (Hosoya-Ohmura et al.
2006; Ferreira et al. 2007), and, similarly, alterations of the GATA-1/FOG-1 ratio can restore the coordinated expansion and terminal differentiation of erythroid cells (Garriga-Canut and Orkin 2004; Kadri et al. 2009; Hasegawa et al. 2012). We therefore investigated whether the forced expression of FOG-1 rescued erythroid differentiation in G1E-ER cells transduced with GATA-1 mutants. G1E-ER cells were first transduced with the FOG-1-EGFP retroviral vector, and the EGFP-positive cell population was selected by cell sorting. The selected cells were transduced with the constructs encoding GATA-1 or GATA-1 mutants. Erythroid maturation was successfully rescued following the transduction of G1EER cells overexpressing FOG-1 with GATA-1 ${ }^{\mathrm{S} 310 \mathrm{~A}}$ or GATA-1 ${ }^{\mathrm{V} 205 \mathrm{G}-\mathrm{S} 310 \mathrm{D}}$. However, even under these conditions, GATA-1 ${ }^{\mathrm{V} 205 \mathrm{G}}$ and GATA-1 ${ }^{\mathrm{V} 205 \mathrm{G}-\mathrm{S} 310 \mathrm{~A}}$ G1E-ER cells failed to differentiate (Fig. 2C,D; Supplemental Fig. S6).

Gata1 ${ }^{\text {S310A }}$ knock-in mice are viable but show subtle subclinical perturbations of $R B C$ homeostasis

The in vitro data and conclusions presented so far (Supplemental Fig. S4) suggest that the phosphorylation of 
GATA-1 at Ser310 has a physiological function. However, these findings are surprising given that transgenic knockin mice bearing the Gata1 $310 \mathrm{~A}$ mutation are viable without anemia (Rooke and Orkin 2006), unlike transgenic knock-in mice possessing the Gata1 ${ }^{\text {V205G }}$ mutation, which die at E11.5 due to severe anemia (Chang et al. 2002). We hypothesized that other mechanisms and pathways compensate for the defective binding of GATA$1^{\mathrm{S} 310 \mathrm{~A}}$ to FOG-1 in vivo but fail to compensate for the GATA-1 ${ }^{\text {V205G }}$ mutation.

We thus re-examined the phenotype of the knock-in Gata1 $^{\text {S310A }}$ mouse (Rooke and Orkin 2006). Consistent with published findings, these mice did not present splenomegaly, and burst forming unit-erythroid (BFU-E) colony counts from fetal liver (E11.5) or bone marrow cells cultured in erythroid differentiation medium M3234 (Stem Cell Technologies) were within the normal range. However, histochemical analysis showed a high abundance of iron-laden macrophages (non-heme iron) in the spleens of Gata1 ${ }^{\text {S310A }}$ mice (Fig. 3A), and this was associated with a low RBC life span and high clearance rate, as assessed by N-hydroxysuccinimidobiotin (NHS-biotin) labeling, without evidence of intravascular hemolysis (Fig. $3 \mathrm{~B})$. The loss of interaction between GATA-1 and FOG-1 compromises erythrocyte membrane integrity (Hasegawa et al. 2012). We therefore compared global RBC membrane protein content of wild-type and Gata $1^{S 310 A}$ mice by SDSPAGE and Coomassie brilliant blue-stained profile (data not shown). We found that RBC membrane proteins were generally present in small amounts in Gata1 ${ }^{\text {S310A }}$ mice. In particular, GLUT-4 transporter levels and glucose uptake were significantly lower in RBCs from Gata1 ${ }^{S 310 A}$ mice than in those from control mice (Fig. $3 \mathrm{C}, \mathrm{D})$. Gata1 ${ }^{\mathrm{S} 310 \mathrm{~A}}$ mice are viable and present no gross abnormalities, but these findings provide evidence of subtle subclinical perturbations of RBC homeostasis.

IGF-1 rescues abnormal ex vivo erythropoiesis caused by the unphosphorylable GATA-1 ${ }^{S 310 A}$ mutant

These observations prompted us to test the hypothesis that specific physiological mechanisms may be activated in Gata1 ${ }^{S 310 A}$ mice to compensate for the deficiency in FOG-1 binding. Of note, it is interesting that a few Gata1 $^{\text {V205G }}$ mice $\left[\mathrm{Tg}\left(\mathrm{Gata}^{*}\right.\right.$ V205G)1Mym], which usually have a lethal phenotype, are born viable (Chang et al. 2002). Transgenic mice survive when GATA- $1^{\mathrm{V} 205 \mathrm{G}}$ is overexpressed (Hasegawa et al. 2012). Thus, the lethal anemia phenotype can be rescued by an excess of GATA-1 ${ }^{\text {V205G }}$ even though this mutation impairs the GATA-1/FOG-1 interaction.

In an effort to find compensatory mechanisms, we compared serum hormone concentrations (insulin, Epo, growth hormone, TGF- $\beta$, and IGF-1) in control and Gata1 ${ }^{S 310 A}$ mice. Only the serum concentration of IGF1 was significantly higher in Gata $1^{S 310 A}$ mice than in control mice (Fig. 4A). We then carried out a colony-forming assay in the absence of IGF-1 and transferrin (M3231 medium, Stem Cell Technologies). We found that BFU-Es from the fetal livers and bone marrow of Gata1 ${ }^{\text {S310A }}$ mice were fewer in number than those from wild-type mice (Fig. 4B,C). By counting the number of cells in a pool of 10 BFU-Es picked randomly, we found that BFUEs from the bone marrow of Gata1 ${ }^{S 310 A}$ mice were smaller. Complementation with IGF-1 or insulin, together with holotransferrin, restored Gata1 ${ }^{S 310 A}$ progenitor counts to levels comparable with those in complete M3234 culture medium (Fig. 4D). This suggests that IGF-1 activates alternative pathways to compensate for the GATA-1 ${ }^{\text {S310A }}$ mutation.

\section{Pharmacological inhibition of IGF-1 receptor (IGF-1R) signaling results in lethal hemolytic anemia in knock-in Gata1 ${ }^{\text {S310A }}$ mice}

We investigated whether the IGF-1R could compensate for the Gata1 ${ }^{S 310 A}$ mutation in vivo. We therefore analyzed erythropoiesis in Gata1 ${ }^{\text {S310A }}$ mice receiving an intraperitoneal injection of cyclolignan picropodophyllin (PPP), a specific inhibitor of IGF-1R activation (Yin et al. 2010). We assessed hematopoietic indices in peripheral blood and used electron microscopy to examine RBC morphology. There were high counts of abnormally shaped RBCs (echinocytes and acanthocytes) in Gata1 ${ }^{S 310 A}$
A
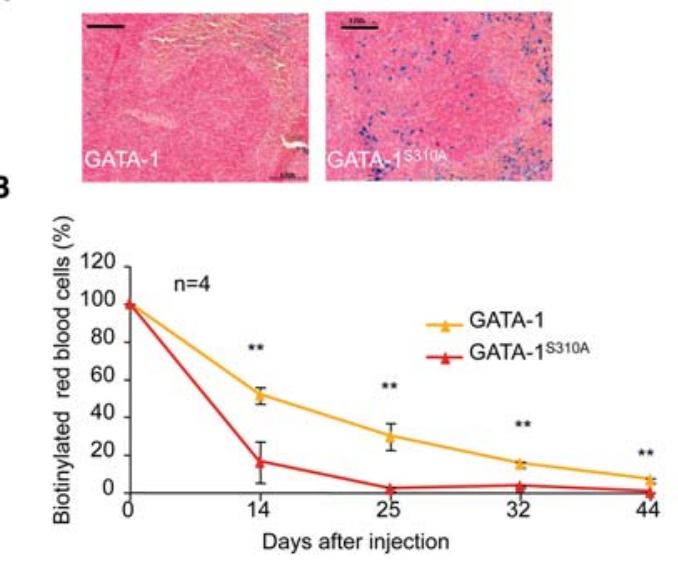

C

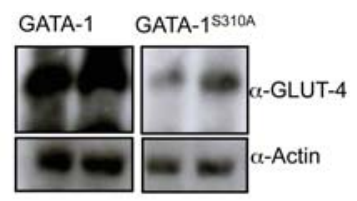

D

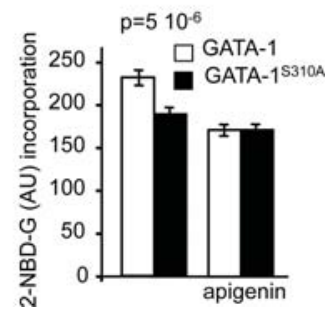

Figure 3. Gata1 ${ }^{S 310 A}$ mice show subtle subclinical perturbations of RBC homeostasis. (A) Perl's Prussian blue staining of spleen sections from Gata1 and Gata1 ${ }^{\text {S310A }}$ mice to visualize non-heme iron deposits within macrophages. Bar, $100 \mu \mathrm{m} .(B)$ RBC clearance after NHS-biotin injection in mice. $n=4 .\left(^{* *}\right) P<0.01$. (C) Western blot analysis of GLUT-4 protein on RBC membranes. $(D)$ Fluorescently tagged glucose uptake assay with peripheral RBCs from Gata1 and Gata1 ${ }^{5310 A}$ mice. 


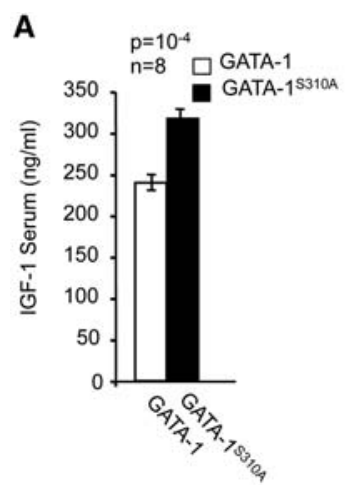

B

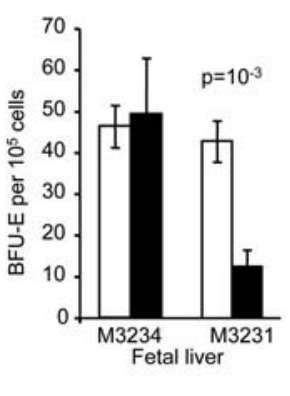

C

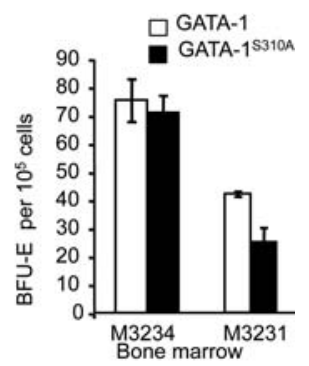

Figure 4. Phosphorylation of GATA-1 at Ser310 and IGF-1 are essential for ex vivo erythropoiesis. (A) Serum concentrations of IGF-1 in Gata1 and Gata ${ }^{\text {S310A }}$ mice were measured by ELISA. $(B, C)$ BFU-E assays of fetal liver $(B)$ and bone marrow $(C)$ cells from Gata1 and Gata1 ${ }^{S 310 A}$ mice. Counts were performed after $12 \mathrm{~d}$ of culture in M3234 methylcellulose or in M3231 medium (without IGF-1 and transferrin; triplicate assay). (D) BFU-E assays of Gata1 and Gata1 ${ }^{\text {S310A }}$ bone marrow cells in M3231 methylcellulose medium supplemented with the various factors, as indicated.

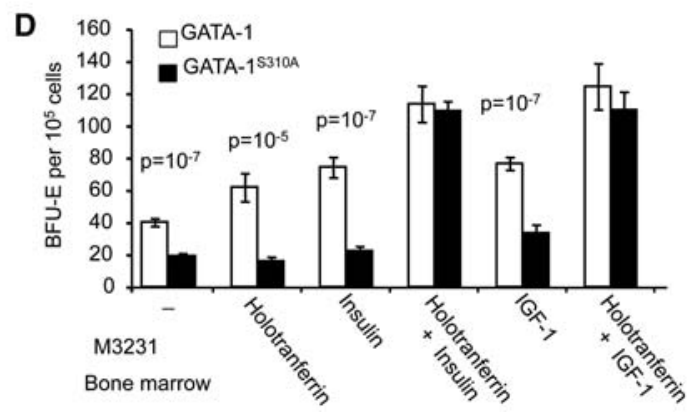

mice after $10 \mathrm{~d}$ of treatment (Fig. 5A-C). After $20 \mathrm{~d}$ of PPP treatment, Gata1 ${ }^{S 310 A}$ mice were moribund and were therefore euthanized. Blood analysis showed severe dyserythropoiesis. Blood smears and electron microscopy analysis showed that the RBC morphology became progressively worse with PPP treatment (RBC fragmentation and ghosts), confirming our observations at $10 \mathrm{~d}$ of treatment (Fig. 5B,C). A low hematocrit and dark blood and free hemoglobin in the serum and urine were detected and were signs of massive hemolytic anemia (Fig. 5D-F). Biochemical analyses of total and direct bilirubin $(12.45 \mu \mathrm{M} \pm 2.69 \mu \mathrm{M}$ and $3.57 \mu \mathrm{M} \pm 0.29 \mu \mathrm{M}$, respectively, vs. $0.9 \mu \mathrm{M} \pm 0.08 \mu \mathrm{M}$ and $0.85 \mu \mathrm{M} \pm 0.32 \mu \mathrm{M}$ for untreated Gata1 ${ }^{\mathrm{S} 310 \mathrm{~A}}$ mice) or lactate dehydrogenase (increase by a factor of 3.8) levels in the sera of Gata1 ${ }^{\text {S310A }}$ PPP-treated mice confirmed the intravascular hemolysis. Reticulocyte counts in Gata1 ${ }^{S 310 A}$ mice reached $87.6 \% \pm 5.3 \%$ (vs. $5.8 \% \pm 0.95 \%$ for wild-type mice) after $20 \mathrm{~d}$ of PPP treatment. Because of the potentially misleading massive hemoglobinemia, hematologic parameters were determined after $20 \mathrm{~d}$ of PPP treatment using both automated and manual methods after separating RBCs from plasma. RBC hemoglobin values after $20 \mathrm{~d}$ of PPP treatment were $15.78 \mathrm{~g} / \mathrm{dL} \pm 0.18 \mathrm{~g} / \mathrm{dL}$ (within normal range for mice) and $4.83 \mathrm{~g} / \mathrm{dL} \pm 0.47 \mathrm{~g} / \mathrm{dL}$ (profound anemia) for GATA-1 ${ }^{W T}$ and Gata ${ }^{\text {S31OA }}$ mice, respectively (Fig. 5A,F). Consistent with total hemoglobin values, only the Gata1 ${ }^{S 310 A}$ mice treated by PPP displayed high plasma and urine concentrations of free hemoglobin (Fig. 5A,F).

Gata1 ${ }^{S 310 A}$ mice displayed massive splenomegaly characteristic of stress-related compensatory erythropoiesis, with large numbers of splenic BFU-E (Fig. 6A) and hyperplasia of the red pulp (Fig. 6B). We evaluated erythroid maturation by scoring the CD71 and Ter119 cell surface markers in spleen and bone marrow cells. The number of Ter119 ${ }^{\text {hi }}$ CD71 ${ }^{\text {hi }}$ basophilic erythroid blasts was high in Gata1 ${ }^{S 310 A}$ mice and was associated with a defect of the later stages of erythroid differentiation (Ter119 hi CD71 ${ }^{\text {low }}$ cells) (Fig. 6C,D). As controls, we treated Gata $^{S 310 A}$ mice with primaquine and $\beta$-thalassemic mice $\left(\mathrm{Hbb}^{\text {th1/th1 }}\right)$ with PPP to exclude oxidative effects of PPP. In both cases, mice survived after $20 \mathrm{~d}$ of treatment, with no detectable effect on erythropoiesis (data not shown). We also treated Gata1 ${ }^{S 310 A}$ mice with rapamycin or pioglitazone because the PPAR $\gamma$ and mTOR pathways are linked to IGF-1R signaling (Belfiore et al. 2009). Neither of these drugs mimicked the phenotype associated with PPP. Thus, signaling via the IGF-1R results in physiological adaptations compensating for the abnormal sequestration of E2F-2 by the pRb/GATA- ${ }^{\mathrm{S} 310 \mathrm{~A}}$ complex.

\section{IGF-1 compensates for the in vivo erythroid defect} caused by GATA-1 $1^{S 310 A}$ by providing an alternative source of E2F-2

We used gene expression studies to identify putative downstream compensatory genes and mechanisms potentially accounting for the survival of Gata1 ${ }^{\text {S310A }}$ mice in the presence of intact IGF-1R signaling. Such mechanisms include the strong expression of GATA-1 target genes, such as AHSP and ALAS2, and E2F-2 overexpression (Fig. 7A). Moving our analysis upstream, we focused on EKLF because this factor cooperates with GATA-1 during almost all aspects of erythroid differentiation (Tallack and Perkins 2010) and also controls cell cycle progression by 
A

\begin{tabular}{|c|c|c|c|c|c|c|c|}
\hline & $\begin{array}{l}\text { Mice } \\
(n=4)\end{array}$ & $\begin{array}{c}\mathrm{RBC} \\
\left(10^{\circ} / \mathrm{mL}\right)\end{array}$ & $\begin{array}{l}\text { HCT } \\
(\%)\end{array}$ & $\begin{array}{c}\text { Plasma } \\
\text { HGB } \\
(\mathrm{g} / \mathrm{dL})\end{array}$ & $\begin{array}{l}\text { RBC } \\
\text { HGB } \\
(\mathrm{g} / \mathrm{dL}) \\
\end{array}$ & $\begin{array}{c}\text { MCV } \\
\text { (fi) }\end{array}$ & $\begin{array}{l}\mathrm{MCHC} \\
(\mathrm{g} / \mathrm{dL})\end{array}$ \\
\hline \multirow{2}{*}{ DMSO } & $W T / Y$ & $9.77(0.24)$ & $40,3(1,06)$ & $0.41(0.03)$ & $12.73(0.46)$ & $41.2(0.22)$ & $31.60(1.07)$ \\
\hline & $\mathrm{KI} / \mathrm{Y}$ & $9.99(0,49)$ & $41.93(2.64)$ & $0.33(0.03)$ & $13.74(0.71)$ & $41.90(0.53)$ & $33.02(2.59)$ \\
\hline \multirow[t]{2}{*}{ PPP } & $\overline{W T / Y}$ & $11,02(0,15)$ & $47.73\left(0.52^{a}\right)$ & $0.43(0.06)$ & $15.78(0.18)$ & $43.25\left(0.12^{a}\right)$ & $33.37(0.3)$ \\
\hline & $\mathrm{KI} / \mathrm{Y}$ & $5,09\left(0,12^{-s}\right)$ & $19.55\left(0.41^{a, b}\right)$ & $15.52(0.38)$ & $4.83(0.47)$ & $38.42\left(0.21^{1, b}\right)$ & ) 24.98 (3.05. \\
\hline
\end{tabular}

a: $p<0.01$ vs DMSO; $b: p<0,01$ versus GATA-1-WT/PPP

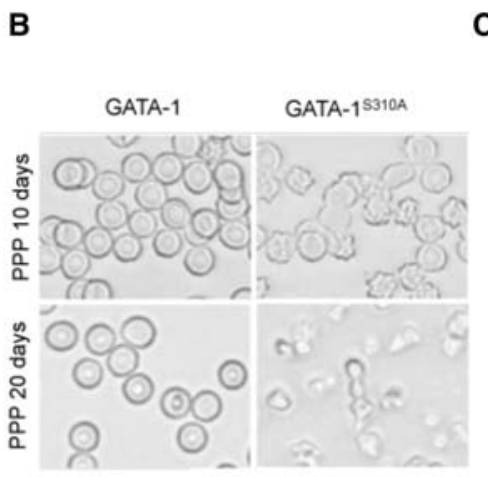

C

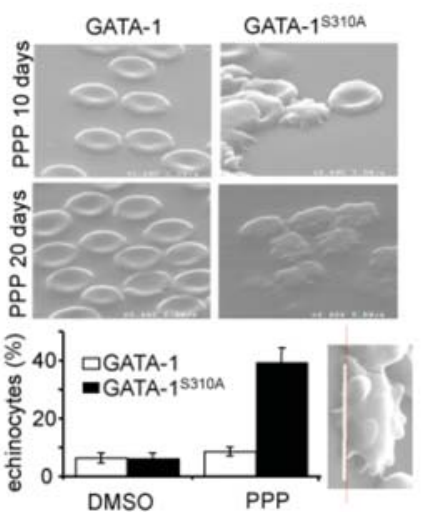

D

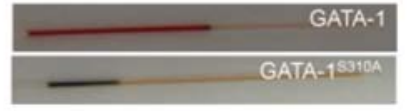

E
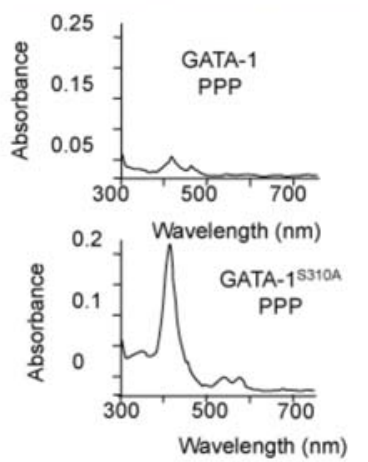

$\mathbf{F}$

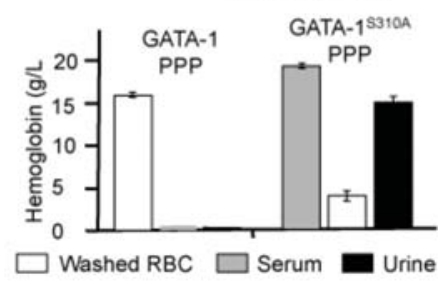

Figure 5. Male mice bearing Gata1 ${ }^{S 310 A}$ alleles die from hemolytic anemia after inhibition of IGF-1R signaling by PPP. (A) Hematopoietic indices of Gata1 (WT/Y) and Gata1 ${ }^{S 310 A}(\mathrm{KI} / \mathrm{Y})$ male mice after $20 \mathrm{~d}$ of PPP treatment. (HGB) Hemoglobin concentrations (after separating RBCs from plasma); (HCT) hematocrit; (MCV) mean corpuscular volume; (MCHC) mean corpuscular hemoglobin concentration. (B) Gata1 and Gata1 ${ }^{S 310 A}$ peripheral blood smears on days 10 and 20 of PPP treatment (630×). (C) Electron microscopy of erythrocytes described in B. (Bottom left) Estimation of the percentage of acanthocyte and echinocyte RBCs on day 10. (Bottom right) Enlarged echinocyte Gata ${ }^{S 310 A}$ RBC. Bar, $5 \mu \mathrm{m}$. (D) Centrifuged microhematocrit capillaries. (E) Spectroscopic analysis of hemoglobin in the plasma. (F) Manual quantification of hemoglobin of washed RBCs and serum in Gata1 and Gata1 ${ }^{\text {S310A }}$ peripheral blood and of urine of the same mice after $20 \mathrm{~d}$ of PPP treatment, as assessed by Drabkin's method. $n=3$ per group.

regulating E2F-2 expression (Pilon et al. 2008; Tallack et al. 2009). We found that the knockdown of Klf1 impaired the compensatory overexpression of E2F-2 in GATA-1 $^{\text {S310A }}$ erythroid cells (Fig. 7A). Gata1 ${ }^{\text {S310A }}$ mice treated with PPP and Klf1-null mice have several relevant phenotypic abnormalities in common (Drissen et al. 2005; Nilson et al. 2006). EKLF was present in similar amounts in both wild-type and Gata1 ${ }^{S 310 A}$ mice, but the expression of PiT1 (Forand et al. 2013), which is strictly dependent on EKLF, was strong in Gata1 ${ }^{S 310 A}$ mice (Fig. 7A). Thus, IGF1 may stimulate the activity of ELKF to compensate at least in part for the GATA-1 ${ }^{\mathrm{S} 310 \mathrm{~A}}$ mutation. We evaluated this possibility by purifying lin $^{-}$bone marrow cells from Gata1 ${ }^{\text {S310A }}$ mice. We then transduced these cells with a lentivirus encoding E2F-2, wild-type EKLF, an EKLF mutant that cannot be phosphorylated at Thr41 (EKLF $\left.{ }^{\mathrm{T} 41 \mathrm{~A}}\right)$,
A
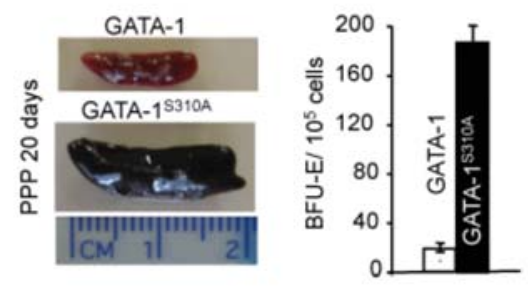

B

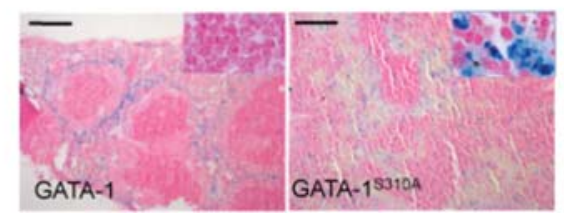

C

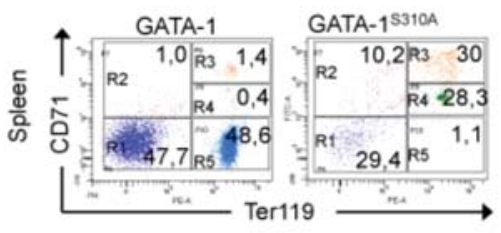

D

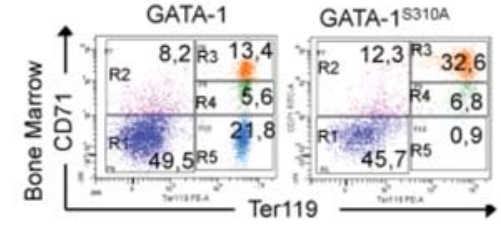

Figure 6. Defective erythroid maturation in Gata1 ${ }^{S 310 A}$ mice treated with PPP. $(A)$ Comparison of spleens from Gata1 and Gata1 ${ }^{S 310 A}$ mice after $20 \mathrm{~d}$ of PPP treatment (left) and BFU-E colony assays of these spleens in M3234 methylcellulose medium (right). $n=4$. (B) Perl's Prussian blue staining of paraffin sections of these spleens. Bar, $200 \mu \mathrm{m}$. $(C, D) \operatorname{Ter1} 19$ ( $X$-axis) and CD71 ( $Y$-axis) FACS analysis of the Sytox-negative living cell population of the spleen $(C)$ and bone marrow $(D)$ from Gata1 and Gata1 ${ }^{\mathrm{S310A}}$ mice. Numbers show the percentage of cells within a particular region. 
A

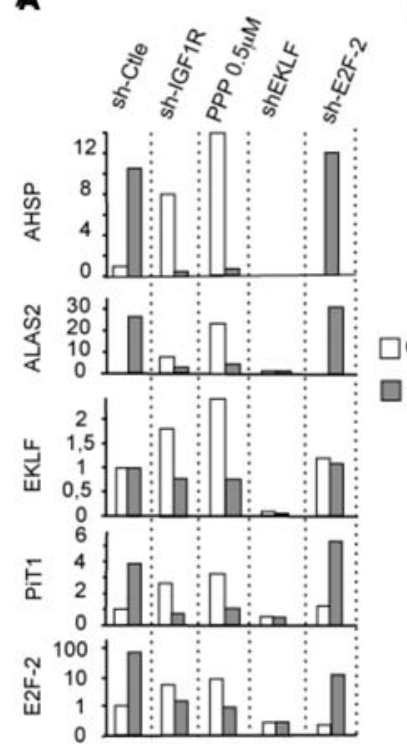

B

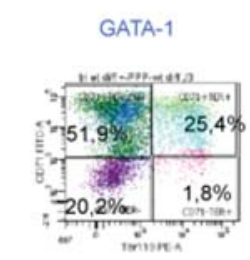

$\square$ GATA-1

GATA-1 133104

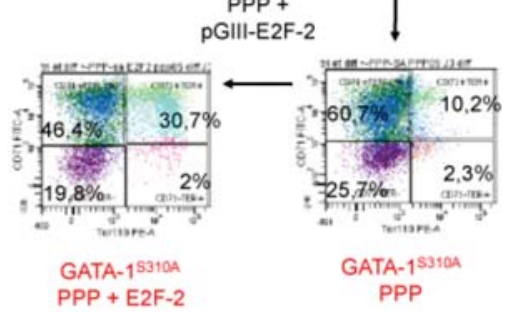

C

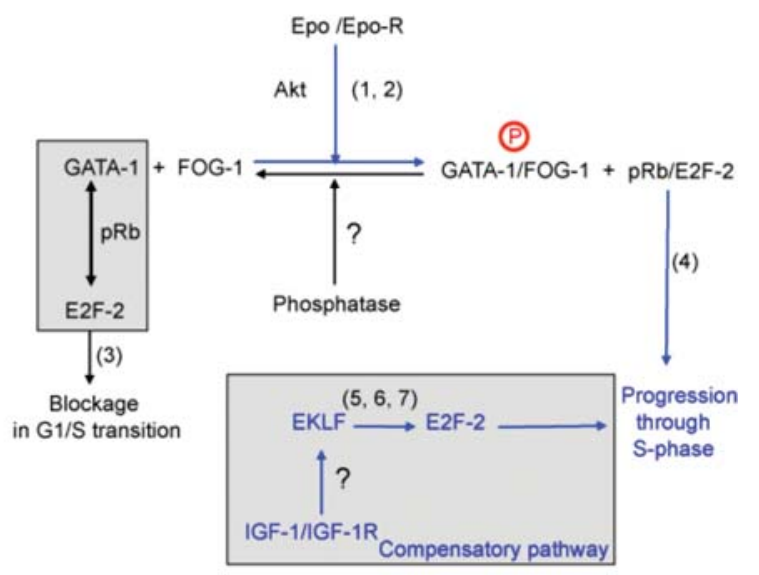

Figure 7. Overexpression of E2F-2 abolishes the PPP-mediated inhibition of terminal differentiation in Gata1 ${ }^{\mathrm{S} 310 \mathrm{~A}}$ erythroid cells ex vivo. (A) Quantitative RT-PCR (qRT-PCR) studies: Primary erythroid cultures of cells derived from the bone marrow of Gata1 and Gata1 ${ }^{S 310 A}$ mice were expanded; transduced with various shRNAs, as indicated (sh-X), on day 2; selected by puromycin treatment on day 5; and transferred to differentiation medium on day 6 . Total mRNA was isolated after $3 \mathrm{~d}$ of differentiation, and qRT-PCR was performed. $(B)$ Ter119 (X-axis) and CD71 (Y-axis) FACS analysis of the living cell population as described in $A$. Numbers show the percentage of cells within a particular region. $(C)$ Schematic model of the coordination of cell proliferation and maturation during erythropoiesis: The sequestration of E2F-2 by GATA-1/pRb slows progression through the G1/S phase of the cell cycle, allowing the differentiation program to start (Kadri et al. 2009). Phosphorylation of GATA-1 by AKT increases its affinity for FOG-1, leading to the dissociation of GATA-1 from the $\mathrm{pRb} / \mathrm{E} 2 \mathrm{~F}$ complex. Consequently, changes to the nuclear concentration of GATA-1/FOG-1 modulate erythroid gene transcription and result in the release of E2F-2 after pRb phosphorylation and the promotion of cell division. Our data suggest that the GATA-1 ${ }^{\text {S310A }}$ mutation impairs the capacity of FOG-1 to dissociate the GATA- $1^{\mathrm{S} 310 \mathrm{~A}} / \mathrm{pRb} / \mathrm{E} 2 \mathrm{~F}-2$ complex, thus promoting E2F-2 sequestration and inhibiting cell proliferation. The IGF-1R pathway counteracts E2F-2 sequestration by stimulating E2F-2 expression. Numbers 1-7 correspond to references as follows: (1) Kadri et al. 2005, (2) Zhao et al. 2006, (3) Kadri et al. 2009, (4) Wong et al. 2011, (5) Fritz and Fajas 2010, (6) Pilon et al. 2008, and (7) Nilson et al. 2006.

or an EKLF mutant mimicking constitutive phosphorylation at Thr41 (EKLF $\left.{ }^{\mathrm{T} 41 \mathrm{D}}\right)$ and analyzed erythroid maturation in vitro. We chose Thr41 mutants of EKLF because the phosphorylation of EKLF at this residue enhances its transcriptional activity (Ouyang et al. 1998). These experiments were carried out in either the presence or absence of PPP. The forced expression of E2F-2-but not that of EKLF, EKLF ${ }^{\mathrm{T} 41 \mathrm{~A}}$, or EKLF ${ }^{\mathrm{T} 41 \mathrm{D}}$-restored the differentiation of GATA-1 ${ }^{\text {S310A }}$ erythroid cells treated with PPP (Fig. 7B; Supplemental Fig. S7; data not shown). Thus, these experiments suggest that the activation of the IGF-1R results in the overexpression of E2F-2, which compensates for the abnormal sequestration of E2F-2 by the pRb/GATA- $1^{\text {S310A }}$ complex. The mechanism by which EKLF regulates E2F-2 expression following activation by IGF-1R remains to be elucidated.

\section{Discussion}

A wealth of knowledge has accumulated during the past three decades to make the biology of erythropoiesis one of the leading fields in the study of tissue differentiation and homeostasis. This includes the identification of the key factors involved (e.g., GATA-1, FOG-1, and EKLF) as well as novel biological concepts (e.g., locus control region [LCR], chromatin insulators, or, more recently, superenhancers). However, key gaps remain in our understanding of the tight coordination between cell proliferation and differentiation, a hallmark of normal erythropoiesis, and its perturbation, as seen in various disorders that include certain types of anemia and leukemia.

We show here that erythroid cell proliferation and differentiation are coupled at the molecular level. Epo-R stimulation activates AKT, which phosphorylates GATA-1 at Ser310, thereby increasing the affinity of GATA-1 for FOG-1. In turn, FOG-1 displaces pRb/E2F-2 from GATA-1, ultimately releasing free, proproliferative E2F-2 (Supplemental Fig. S4A,B).

The phosphorylation of GATA-1 at Ser310 thus has several consequences: (1) It controls the affinity of GATA-1/ FOG-1 binding; (2) it regulates the dissociation of $\mathrm{pRb} /$ E2F-2 from GATA-1; (3) it determines the FOG-1-mediated control of GATA-1, GATA-1/FOG-1, and E2F-2-regulated genes; (4) it coordinates GATA-1 and E2F-2 activities; and (5) it determines the potential transcriptional activity of the GATA-1/pRb/E2F-2 complex at GATA and/or E2F DNA-binding sequences (this last contention remains to be demonstrated). The net effects of 
GATA-1 phosphorylation at Ser310 are to decrease and increase the respective concentrations of free GATA-1 and free E2F-2 due to the relative amounts and affinities of the factors involved. This balance (opposite variations in free GATA-1 and free E2F-2) participates in the coordination of cell proliferation and maturation during erythropoiesis in the presence of Epo, with the differential phospho-binding of GATA-1 to FOG-1 as a molecular pivot (Supplemental Fig. S4C).

As a stepwise process, the coupling of cell proliferation and differentiation is likely to involve specific subsets of genes that are activated and repressed in a defined order. FOG-1 plays contrasting roles at different loci. For instance, at the Gata2 locus, FOG-1/GATA-1 repress a subset of GATA-1 target genes (GATA switch) (Grass et al. 2006) while recruiting the NuRD repressor (Gao et al. $2010)$. At the $\beta$-globin locus, GATA-1/FOG-1 are primarily activators of the LCR while also recruiting NuRD (Gregory et al. 2010).

The putative importance of GATA-1 phosphorylation has been discussed (Kadri et al. 2005; Zhao et al. 2006). However, data from transgenic Gata1 ${ }^{\text {S310A }}$ knock-in mice were puzzling because these mice are viable and not even anemic (Rooke and Orkin 2006). Here, we were able to reconcile this discrepancy by uncovering a compensatory pathway. We found that excess IGF-1 conferred a normal phenotype in Gata1 $1^{S 310 A}$ mice. The abnormal sequestration of E2F-2 within the GATA- $1^{\text {S310A }} / \mathrm{pRb}$ complex of Gata ${ }^{S 310 A}$ mice was counteracted by the overexpression of E2F-2 triggered by IGF-1. However, we were unable to identify the specific pathway involved in the IGF-1-mediated up-regulation of E2F-2 expression, although we observed that the phenotype of Gata1 ${ }^{\text {S310A }}$ mice treated with the IGF-1R inhibitor PPP closely resembled that of Klf1-null mice (Drissen et al. 2005; Nilson et al. 2006), and both EKLF and GATA-1 are involved in the regulation of erythroid genes and in the control of E2F-2 transcription (Pilon et al. 2008; Tallack et al. 2009). We showed that IGF-1-mediated E2F-2 expression requires the activation of EKLF but does not depend on its phosphorylation at Thr41 (data not shown). We did not determine how IGF-1 activates EKLF, but several post-transcriptional modifications of EKLF have been described, and we will examine these modifications in subsequent studies. For instance, the dominant effect of the E339D mutation of EKLF in Nan mice, in which E2F-2 is selectively inhibited (Siatecka et al. 2010), may provide further clues to understand how EKLF activation regulates E2F-2 transcription.

Collectively, our data suggest a molecular model (Fig. 7C) in which FOG-1 has several key functions in the coordination of erythroid proliferation and differentiation and in which GATA-1, FOG-1, EKLF, AKT, pRb, and E2F-2 are part of a dynamic equilibrium controlled by Epo-R and IGF-1R. This model provides new insight into the understanding of both normal and pathological erythropoiesis in humans, such as that observed in various myeloproliferative disorders in which AKT kinase is constitutively activated. Similarly, this model helps to explain several pathogenic mutations of Gata1 for which molecular and physiological explanations were lacking /Crispino and Weiss 2014) despite multiomic and knock-in experimental approaches.

The somatic V617F mutation of JAK2 that is found in almost all polycythemia vera patients (Vainchenker and Constantinescu 2005) may disturb the equilibrium between GATA-1/pRb/E2F-2 and GATA-1/FOG-1: Hypersensitivity to IGF-1 (Staerk et al. 2005), high levels of phosphorylated GATA-1 (Geron et al. 2008), and IGFBP1 overexpression (Mirza et al. 1997) characterize progenitor cells from polycythemia vera patients, and our model may form the basis of new molecular interpretations of this disease. Activation of IGF-1 signaling together with expression of a truncated Epo-R induces autosomal dominant erythrocytosis in humans (De La Chapelle et al. 1993; Damen et al. 1998). In this case, IGF-1 may compensate for a lack of Epo-induced signaling by stimulating E2F-2 expression. In patients possessing inherited N-terminally deleted GATA-1 protein (GATA-1s), previously described in acute megakaryoblastic leukemia associated with Down syndrome (Wechsler et al. 2002), IGF-1 is required for cell survival and leads to the uncontrolled proliferation of trisomy 21 fetal progenitors (Klusmann et al. 2010). GATA-1s has since been found in patients with lethal anemia (Hollanda et al. 2006) and patients with Diamond-Blackfan anemia (Sankaran et al. 2012). GATA-1s is translated from a downstream ATG initiation codon encoding $\mathrm{Met}^{84}$, which disrupts the association of GATA-1 with pRb/E2F-2 (Kadri et al. 2009); therefore, the defect in erythropoiesis in these two diseases may be associated with the loss of this interaction and an increase in the amount of free E2F-2.

Mutations that modify the affinity of FOG-1 binding to GATA-1 cause thrombocytopenia and anemia. The severity of anemia is correlated with the extent to which the interaction is disrupted (Crispino 2005) and the GATA-1 ${ }^{\mathrm{V} 205 \mathrm{G}}$ mutation causes lethal anemia. We show that (1) Ser310 of the GATA-1 ${ }^{\text {V205G }}$ mutant is not phosphorylated by AKT, (2) constitutive Ser310 phosphorylation in the GATA-1 ${ }^{\text {V205G }}$ (GATA-1 ${ }^{\text {V205G-S310D }}$ ) mutant is sufficient to restore partial G1E-ER erythroid differentiation similar to that observed with the GATA- $1^{\mathrm{S} 310 \mathrm{~A}} \mathrm{mu}-$ tant, and (3) GATA-1 $205 \mathrm{G}-\mathrm{S} 310 \mathrm{D}$ expression coupled with FOG-1 overexpression fully rescues G1E-ER differentiation such that GATA-1 ${ }^{\text {V205G-S310D }}$ and GATA- $1^{\text {S310A }}$ seem to have similar properties. These various observations contribute to our understanding of the molecular mechanisms of GATA-1 action and will help to orient new research to improve our understanding of erythropoiesis disorders associated with GATA-1 mutations. Systematic analyses of IGF-1 concentrations in the serum of patients with mild chronic anemia will be useful to assess potential perturbations of the complex equilibrium presented here.

The connection between Epo, cell expansion, and the regulation of energy homeostasis in adipocytes (Teng et al. 2011) suggests that a specific combination of various receptors modulates homeostasis for various cell types. This observation also raises the possibility that similar $\mathrm{pRb} / \mathrm{E} 2 \mathrm{~F}$ interactions with other GATA/FOG family 
members may be involved in the coordination of cell differentiation and proliferation in other tissues.

\section{Materials and methods}

\section{Plasmid constructions}

Human Gata1, Gata1 mutants (Gata1 $^{\text {S310A }}$, Gata1 ${ }^{\text {S310D }}$, Human Gata1, Gata1 mutants (Gata1 Gatal $^{\text {V205G }}$, Gata1 ${ }^{\text {V205G-S310A }}$, Gata1 ${ }^{\text {V205G-S310D) }}$, and mouse Fog1 cDNA were subcloned in the retroviral vector Migr as previously described (Kadri et al. 2005). Lentivectors encoding mE2F-2 (pLenti-GIII-CMV-mE2F-2-SV40-RFP-2A-Puro [LV495474]) and control backbone (pLentiGIII-CMV-RFP-2A-Puro-Blank control vector [LV591]) were purchased from Applied Biological Materials.

\section{Retroviral and lentiviral transduction and transfection}

Retroviral production and cell transduction were performed as previously described (Kadri et al. 2005). GFP-positive cells were then sorted by flow cytometry (BD FACSAria, Beckman Coulter). Lentiviruses were produced according to the manufacturer's instructions with Lenti-Combo packaging mix (Gentaur, LV003). shRNA lentiviral particles (control shRNA [sc-108080], mIGF1R $\alpha / \beta$ shRNA [sc-35638-V], mEKLF shRNA [sc-37832-V], and mE2F-2 shRNA [sc-29299-V]) were purchased from Santa Cruz Biotechnology. Three days after lentivirus infection, transduced cells were selected by overnight exposure to $1 \mu \mathrm{g} / \mathrm{mL}$ puromycin dihydrochloride (Sigma). NIH-3T3 cells were transfected in the presence of Lipofectamine 2000 reagent (Life Technologies).

\section{Cell culture, cell proliferation, and erythroid} differentiation analysis

UT-7 cells were maintained in modified Eagle's medium ( $\alpha$-MEM) containing $10 \%$ fetal calf serum (FCS), 2 mM L-glutamine, $10 \mathrm{U} /$ $\mathrm{mL}$ penicillin, $100 \mu \mathrm{g} / \mathrm{mL}$ streptomycin, and $2 \mathrm{U} / \mathrm{mL}$ recombinant human Epo (Bio Basic, RC213-15). NIH-3T3 cells were maintained in Dulbecco's modified Eagle's medium (DMEM) containing $10 \%$ FCS, $2 \mathrm{mM}$ L-glutamine, $10 \mathrm{U} / \mathrm{mL}$ penicillin, and $100 \mu \mathrm{g} / \mathrm{mL}$ streptomycin. Gata1 ${ }^{-/-}$G1E (Weiss et al. 1997) or G1E-ER (Gregory et al. 1999) cells were used as a model of erythropoiesis after trans-complementation with GATA-1 or GATA-1 mutants and grown as previously described (Kadri et al. 2005). Uptiblue reagent (Interchim, UP669412) was used to monitor cell proliferation by fluorimetry at $590 \mathrm{~nm}$ (Mithras LB940, Berthold) as previously described (Kadri et al. 2005). Erythroid differentiation was assessed by scoring blue cells after benzidine staining to detect hemoglobin.

Preparation of nuclear extracts, protein binding, and expression studies

For the preparation of nuclear extract, cells were washed once with PBS and incubated for $10 \mathrm{~min}$ at $4^{\circ} \mathrm{C}$ in buffer A $10 \mathrm{mM}$ HEPES at $\mathrm{pH} 7.6,3 \mathrm{mM} \mathrm{MgCl}, 10 \mathrm{mM} \mathrm{KCl}, 5 \%$ glycerol, $0.5 \%$ NP-40) containing phospho-tyrosine phosphatase inhibitors (1 $\mathrm{mM} \mathrm{Na}_{2} \mathrm{VO}_{4}$ ), phospho-serine/threonine phosphatase inhibitors $(20 \mathrm{mM} \mathrm{NaF}, 1 \mathrm{mM}$ sodium pyrophosphate, $25 \mathrm{mM} \beta$-glycerophosphate), and proteinase inhibitors. After centrifugation, nuclear pellets were resuspended in buffer A containing $300 \mathrm{mM}$ $\mathrm{KCl}$. Immunoprecipitation was performed on equal amounts of nuclear extracts (500 $\mu \mathrm{g}$ per point) with $5 \mu \mathrm{g}$ of the specific antibodies indicated or, as a control, non-immune-related antibodies. Oligonucleotide pull-down assays were performed as previously described (Kadri et al. 2005). Precipitated proteins and $25 \mu \mathrm{g}$ of nuclear extract before immunoprecipitation (input) and after each immunoprecipitation were analyzed by Western blotting with the antibodies indicated. Nucleophosmin (NPM) (Santa Cruz Biotechnology, sc-6013R) was used as a negative control for the specificity of coimmunoprecipitation.

For analysis of the glucose transporter GLUT-4 expression, peripheral blood was collected, washed twice with PBS, and lysed with $5 \mathrm{mM}$ phosphate buffer $(\mathrm{pH} 8)$. After centrifugation $\left(16,000 \mathrm{rpm}\right.$ at $\left.4^{\circ} \mathrm{C}\right)$, RBC membranes were washed three times with hypotonic buffer. Pellets were resuspended in Laemmli buffer and sonicated. Loading volume was adjusted to the original number of RBCs determined with a Medonic CA620 hemocytometer, and Western blot was performed with the $\alpha$-GLUT- 4 antibody (Abcam, ab65267).

\section{Treatment of mice with drugs}

All procedures were approved by the Animal Care and Use Committee of the Commissariat à l'Energie Atomique et aux Énergies Alternatives (CEA). Mice were generated by crossing $\mathrm{X}^{\text {Gata1S310A }}$ / $\mathrm{Y}$ male mice with $\mathrm{X}^{\text {Gata1S310A }} / \mathrm{X}^{\text {Gata1 }}$ female mice (Rooke and Orkin 2006) and housed at the CEA mouse facility (Fontenayaux-Roses). All experiments were conducted on 12-wk-old $\mathrm{X}^{\text {Gata1S310A }} / \mathrm{Y}$ and $\mathrm{X}^{\mathrm{Gata1}} / \mathrm{Y}$ male mice. Mice received daily intraperitoneal injections for $20 \mathrm{~d}$ with (1) PPP (Tocris Biosciences, 477-47-4) at a dose of $10 \mathrm{mg} / \mathrm{kg}$ every $12 \mathrm{~h},(2)$ primaquine (Sigma-Aldrich, 63-45-6) at a dose of $10 \mathrm{mg} / \mathrm{kg}$ every $12 \mathrm{~h}$, (3) rapamycin (Sigma-Aldrich, 200-664-3) at a dose of $2 \mathrm{mg} / \mathrm{kg}$ per day, and (4) pioglitazone (Bertin Pharma, 71745) at a dose of $10 \mathrm{mg} / \mathrm{kg}$ per day. All chemicals were dissolved in dimethyl sulfoxide (DMSO) before reconstitution in saline containing 5\% DMSO for injection.

Hematological analysis, primary erythroid culture, and colony assays

Peripheral blood was collected into heparin-coated capillary tubes by retro-orbital sinus bleeding. Hematopoietic parameters were determined with a hemocytometer (Medonic, CA620). BFU-E assays were performed by dispensing $1 \times 10^{5}$ cells into 35-mm plates in methylcellulose medium (MethoCult M3234 and M3231, Stem Cell Technologies) supplemented with 2 U/ $\mathrm{mL}$ human recombinant Epo, $10 \mathrm{ng} / \mathrm{mL}$ murine recombinant stem cell factor (SCF) (Peprotech, 250-03), 2 mM L-glutamine, $10 \mathrm{U} / \mathrm{mL}$ penicillin, and $100 \mu \mathrm{g} / \mathrm{mL}$ streptomycin. The MethoCult M3231 was complemented with $0.5 \mu \mathrm{g} / \mathrm{mL}$ human IGF-1 (Increlex, Ipsen Pharma), $10 \mu \mathrm{g} / \mathrm{mL}$ human recombinant insulin (Sigma, 91077C), and/or $200 \mu \mathrm{g} / \mathrm{mL}$ iron-saturated human holotransferrin (Sigma). Cells were cultured for $12 \mathrm{~d}$ at $37^{\circ} \mathrm{C}$ with $5 \% \mathrm{CO}_{2}$, and benzidine-positive BFU-E colonies were then counted.

For erythroid primary culture, bone marrow cells were flushed from femurs and tibias. The $\mathrm{Lin}^{-} \mathrm{Sca}-1^{-}$cell fraction was purified by positive depletion with the Lineage cell depletion kit (Miltenyi Biotec, 130-090-858) coupled with the anti-mouse Sca-1 biotin-coupled antibody (eBioscience, 13-5981). Cells were first cultured in a serum-free expansion medium containing IMDM, 15\% BIT9500 (Stem Cell Technologies), 2 mM L-glutamine, 10 $\mathrm{U} / \mathrm{mL}$ penicillin and $100 \mu \mathrm{g} / \mathrm{mL}$ streptomycin, $1 \mathrm{U} / \mathrm{mL}$ Epo, 100 $\mathrm{ng} / \mathrm{mL} \mathrm{SCF}$, and $1 \mu \mathrm{M}$ dexamethasone (Sigma). After $6 \mathrm{~d}$, cells were washed in PBS, depleted of mature erythroid cells by immune-magnetic depletion against Ter119 (Miltenyi Biotec, 130049-901), and cultured for $3 \mathrm{~d}$ in differentiation medium (2 mM L-glutamine, $10 \mathrm{U} / \mathrm{mL}$ penicillin and $100 \mu \mathrm{g} / \mathrm{mL}$ streptomycin, 
$4 \mathrm{U} / \mathrm{mL}$ Epo, $0.5 \mathrm{mg} / \mathrm{mL}$ iron-saturated human holotransferrin; StemPro34 plus nutrient supplement [Life Technologies]).

Reticulocyte counts in peripheral blood were determined manually on blood smears stained with new methylene blue (Sigma).

\section{Flow cytometry analysis}

Phycoerythrin-conjugated anti-mouse Ter119 (Ter119-PE) (BD Pharmingen, 553673), APC-conjugated anti mouse CD117 (cKit) (BD Pharmingen, 553356), and FITC-conjugated anti-mouse CD71 (BD Pharmingen, 553266) were used for the surface labeling of cells. Purified anti-mouse CD16/32 antibody (eBioscience, 140161) was added to block nonspecific binding to Fc $\gamma$ R. For each experiment, Sytox Blue nucleic acid stain (Life Technologies, S34857) was used to exclude dead cells. Flow cytometry was performed with a BD FACSCantoII or BD LSRFortessa, and data were analyzed with BD FACSDiva software.

\section{Histological and cytological analysis}

Histological and cytological analyses were performed with standard protocols. Spleens were fixed in 3.7\% PFA in $0.02 \mathrm{M}$ phosphate buffer, embedded in paraffin, and stained. Perl's Prussian blue staining was performed according to standard protocols (HistoPerls, RAL). For the scanning electron microscopy analysis, peripheral blood was fixed in $0.75 \%$ glutaraldehyde solution in 0.1 M phosphate buffer (pH 7.4). Samples were viewed with a CM12 LaB6 electron microscope.

\section{Confocal microscopy analysis}

We determined the subcellular distribution of the GATA-1 mutants as described by Lee et al. (2009) on a Leica TCS SP8 confocal microscope. Anti-GATA-1 antibody (Sigma, G0290) and Alexa fluor 488 donkey anti-rabbit (Molecular Probes, A21206) were used in these analyses. Acquisition of DAPI signal and GATA-1 immunofluorescence were performed sequentially.

\section{Hemoglobin detection assay and chemical analysis}

Drabkin's reagent (Sigma, D5941) was used for the quantitative colorimetric determination of hemoglobin according to the manufacturer's instructions. Peripheral blood was collected in heparin-coated tubes, and serum was separated by centrifugation at $10,000 \mathrm{~g}$ for $5 \mathrm{~min}$. Serum LDH activity was measured by a colorimetric assay according to the manufacturer's instructions (Sigma, MAK066). Total and direct bilirubin concentrations were determined at $530 \mathrm{~nm}$ by the Malloy-Evelyn method (Biolabo, 80403).

\section{Measurement of the life span of RBCs}

NHS-biotin (50 mg/kg body weight; Sigma, H1759) was injected intravenously into Gata1 and Gata $1^{\mathrm{S} 10 \mathrm{~A}}$ mice. At various time points, RBCs were collected, stained with FITC-coupled streptavidin (eBioscience, 11-4317-87) and Ter119-PE, and analyzed by flow cytometry. For each mouse, the percentage of FITC-positive RBC (Ter119-positive) obtained at day 1 after injection was considered to correspond to $100 \%$ staining.

\section{Deoxyglucose uptake}

RBCs from Gata1 and Gata1 ${ }^{S 310 A}$ mice were collected and incubated with fluorescently tagged glucose according to the manu- facturer's recommendations (Cayman's glucose uptake cellbased assay kit, Bertin Pharma). Analyses were performed with a flow cytometer, and an inhibitor of glucose transport, apigenin, was used as a control.

\section{Determination of IGF-1 concentration}

Serum concentrations of IGF-1 in mice were determined by ELISA according to the kit manufacturer's instructions (Quantikine ELISA mouse/rat IGF-1 immunoassay kit, R\&D Systems).

\section{Quantitative real-time RT-PCR ( $q P C R$ )}

Total RNA was extracted from primary erythroid cell cultures with the array pure nano-scale RNA purification kit (Epicentre), treated with DNase I (Invitrogen), and quantified with a Nanodrop analyzer. Reverse transcription was carried out with SuperScript III (Invitrogen). The TaqMan gene expression assay (Applied Biosystems) was used with probes specific for mouse cDNA (AHSP, Mm04214740_u1; ALAS2, Mm00802083_m1; EKLF, Mn04208330_g1; PiT1, Mm00441492_m1; and E2F-2, Mm00624964_m1). An ABI Prism 7300 system with TaqMan FAM dye was used for qPCR, and qPCR results were normalized with respect to those obtained for $18 \mathrm{~S}$ cDNA with specific primers (18S, Hs99999901/S1).

\section{Acknowledgments}

We thank Saghi Ghaffari (Mount Sinai Hospital, New York, USA) and Stuart Orkin (Harvard Medical School, Boston, USA) for providing Gata $1^{\text {S310A }}$ mice; Daphna Fenel and Guy Schoehn (UMR 5075, Institut de Biologie Structurale Jean-Pierre Ebel, Commissariat à l'Energie Atomique et aux Énergies Alternatives [CEA], Grenoble, France) for electron microscopy analysis; Maria-Elena Noguera (Hopital St Louis, Paris, France), Yves Beuzard, Olivier Negre, and Emmanuel Payen (L'Institut des Maladies Emergentes et des Thérapies Innovantes (IMETI)/CEA, Fontenay aux Roses, France) for their assistance with cytological analysis; and Antonio Cosma, Sabrina Guenounou, and Christelle Cassan (IMETI/CEA, Fontenay aux Roses, France) for their help with flow cytometry analysis. We thank Lamya Irbah and the microscopy facility at Institut de Recherche en Radiobiologie Cellulaire et Moléculaire (iRCM)/CEA for technical advice. This work was supported by the Commissariat à l'Energie Atomique et aux Énergies Alternatives, Institut National de la Santé et de la Recherche Médicale, and University of Paris-Saclay and a grant from the Agence Nationale de la Recherche (Chaire d'Excellence and Industrielle to P.L.).

\section{References}

Belfiore A, Genua M, Malaguarnera R. 2009. PPAR- $\gamma$ agonists and their effects on IGF-I receptor signaling: implications for cancer. PPAR Res 2009: 830501.

Cantor AB, Orkin SH. 2002. Transcriptional regulation of erythropoiesis: an affair involving multiple partners. Oncogene 21: 3368-3376.

Chang AN, Cantor AB, Fujiwara Y, Lodish MB, Droho S, Crispino JD, Orkin SH. 2002. GATA-factor dependence of the multitype zinc-finger protein FOG-1 for its essential role in megakaryopoiesis. Proc Natl Acad Sci 99: 9237-9242.

Chlon TM, Crispino JD. 2012. Combinatorial regulation of tissue specification by GATA and FOG factors. Development 139: 3905-3916. 
Ciovacco WA, Raskind WH, Kacena MA. 2008. Human phenotypes associated with GATA-1 mutations. Gene 427: 1-6.

Crispino JD. 2005. GATA1 in normal and malignant hematopoiesis. Semin Cell Dev Biol 16: 137-147.

Crispino JD, Weiss MJ. 2014. Erythro-megakaryocytic transcription factors associated with hereditary anemia. Blood 123: 3080-3088.

Damen JE, Krosl J, Morrison D, Pelech S, Krystal G. 1998. The hyperresponsiveness of cells expressing truncated erythropoietin receptors is contingent on insulin-like growth factor-1 in fetal calf serum. Blood 92: 425-433.

De La Chapelle A, Traskelin A, Juvonen E. 1993. Truncated erythropoietin receptor causes dominantly inherited benign human erythrocytosis. Proc Natl Acad Sci 90: 4495-4499.

Drissen R, von Lindern M, Kolbus A, Driegen S, Steinlein P, Beug H, Grosveld F, Philipsen S. 2005. The erythroid phenotype of EKLF-null mice: defects in hemoglobin metabolism and membrane stability. Mol Cell Biol 25: 5205-5214.

Dubart A, Romeo PH, Vainchenker W, Dumenil D. 1996. Constitutive expression of GATA-1 interferes with the cell-cycle regulation. Blood 87: 3711-3721.

Ferreira R, Wai A, Shimizu R, Gillemans N, Rottier R, von Lindern M, Ohneda K, Grosveld F, Yamamoto M, Philipsen S. 2007. Dynamic regulation of Gata factor levels is more important than their identity. Blood 109: 5481-5490.

Forand A, Beck L, Leroy C, Rousseau A, Boitez V, Cohen I, Courtois G, Hermine O, Friedlander G. 2013. EKLF-driven PIT1 expression is critical for mouse erythroid maturation in vivo and in vitro. Blood 121: 666-678.

Fritz V, Fajas L. 2010. Metabolism and proliferation share common regulatory pathways in cancer cells. Oncogene 29: 4369-4377.

Gao Z, Huang Z, Olivey HE, Gurbuxani S, Crispino JD, Svensson EC. 2010. FOG-1-mediated recruitment of NuRD is required for cell lineage re-enforcement during haematopoiesis. EMBO J 29: 457-468.

Garriga-Canut M, Orkin SH. 2004. Transforming acidic coiledcoil protein 3 (TACC3) controls friend of GATA-1 (FOG-1) subcellular localization and regulates the association between GATA-1 and FOG-1 during hematopoiesis. I Biol Chem 279: 23597-23605.

Geron I, Abrahamsson AE, Barroga CF, Kavalerchik E, Gotlib J, Hood JD, Durocher J, Mak CC, Noronha G, Soll RM, et al. 2008. Selective inhibition of JAK2-driven erythroid differentiation of polycythemia vera progenitors. Cancer Cell 13: 321-330.

Grass JA, Jing H, Kim SI, Martowicz ML, Pal S, Blobel GA, Bresnick EH. 2006. Distinct functions of dispersed GATA factor complexes at an endogenous gene locus. Mol Cell Biol 26: 7056-7067.

Gregory T, Yu C, Ma A, Orkin S, Blobel G, Weiss M. 1999. GATA1 and erythropoietin cooperate to promote erythroid cell survival by regulating bcl- $\mathrm{x}_{\mathrm{L}}$ expression. Blood 94: 87-96.

Gregory GD, Miccio A, Bersenev A, Wang Y, Hong W, Zhang Z, Poncz $M$, Tong $W$, Blobel GA. 2010. FOG1 requires NuRD to promote hematopoiesis and maintain lineage fidelity within the megakaryocytic-erythroid compartment. Blood 115: 2156-2166.

Hasegawa A, Shimizu R, Mohandas N, Yamamoto M. 2012. Mature erythrocyte membrane homeostasis is compromised by loss of the GATA1-FOG1 interaction. Blood 119: 2615-2623.

Hollanda LM, Lima CS, Cunha AF, Albuquerque DM, Vassallo J, Ozelo MC, Joazeiro PP, Saad ST, Costa FF. 2006. An inherited mutation leading to production of only the short isoform of
GATA-1 is associated with impaired erythropoiesis. Nat Genet 38: 807-812.

Hong W, Nakazawa M, Chen YY, Kori R, Vakoc CR, Rakowski C, Blobel GA. 2005. FOG-1 recruits the NuRD repressor complex to mediate transcriptional repression by GATA-1. EMBO $2 \mathbf{2 4 :}$ 2367-2378.

Hosoya-Ohmura S, Mochizuki N, Suzuki M, Ohneda O, Ohneda K, Yamamoto M. 2006. GATA-4 incompletely substitutes for GATA-1 in promoting both primitive and definitive erythropoiesis in vivo. J Biol Chem 281: 32820-32830.

Kadri Z, Maouche-Chretien L, Rooke HM, Orkin SH, Romeo PH, Mayeux P, Leboulch P, Chretien S. 2005. Phosphatidylinositol 3-kinase/Akt induced by erythropoietin renders the erythroid differentiation factor GATA-1 competent for TIMP-1 gene transactivation. Mol Cell Biol 25: 7412-7422.

Kadri Z, Shimizu R, Ohneda O, Maouche-Chretien L, Gisselbrecht S, Yamamoto M, Romeo PH, Leboulch $\mathrm{P}$, Chretien S. 2009. Direct binding of pRb/E2F-2 to GATA-1 regulates maturation and terminal cell division during erythropoiesis. PLOS Biol 7: e1000123.

Klusmann JH, Godinho FJ, Heitmann K, Maroz A, Koch ML, Reinhardt D, Orkin SH, Li Z. 2010. Developmental stage-specific interplay of GATA1 and IGF signaling in fetal megakaryopoiesis and leukemogenesis. Genes Dev 24: 1659-1672.

Kuhrt D, Wojchowski DM. 2015. Emerging EPO and EPO receptor regulators and signal transducers. Blood 125: 3536-3541.

Lacombe C, Mayeux P. 1998. Biology of erythropoietin. Haematologica 83: 724-732.

Lamonica JM, Vakoc CR, Blobel GA. 2006. Acetylation of GATA1 is required for chromatin occupancy. Blood 108: 3736-3738.

Lee HY, Johnson KD, Fujiwara T, Boyer ME, Kim SI, Bresnick EH. 2009. Controlling hematopoiesis through sumoylation-dependent regulation of a GATA factor. Mol Cell 36: 984-995.

Letting DL, Chen YY, Rakowski C, Reedy S, Blobel GA. 2004. Context-dependent regulation of GATA-1 by friend of GATA-1. Proc Natl Acad Sci 101: 476-481.

Mirza AM, Ezzat S, Axelrad AA. 1997. Insulin-like growth factor binding protein-1 is elevated in patients with polycythemia vera and stimulates erythroid burst formation in vitro. Blood 89: $1862-1869$.

Munugalavadla V, Dore LC, Tan BL, Hong L, Vishnu M, Weiss MJ, Kapur R. 2005. Repression of c-kit and its downstream substrates by GATA-1 inhibits cell proliferation during erythroid maturation. Mol Cell Biol 25: 6747-6759.

Nilson DG, Sabatino DE, Bodine DM, Gallagher PG. 2006. Major erythrocyte membrane protein genes in EKLF-deficient mice. Exp Hematol 34: 705-712.

Ouyang L, Chen X, Bieker JJ. 1998. Regulation of erythroid Kruppel-like factor (EKLF) transcriptional activity by phosphorylation of a protein kinase casein kinase II site within its interaction domain. J Biol Chem 273: 23019-23025.

Parrella S, Aspesi A, Quarello P, Garelli E, Pavesi E, Carando A, Nardi M, Ellis SR, Ramenghi U, Dianzani I. 2014. Loss of GATA-1 full length as a cause of Diamond-Blackfan anemia phenotype. Pediatr Blood Cancer 61: 1319-1321.

Patient RK, McGhee JD. 2002. The GATA family /vertebrates and invertebrates). Curr Opin Genet Dev 12: 416-422.

Pilon AM, Arcasoy MO, Dressman HK, Vayda SE, Maksimova YD, Sangerman JI, Gallagher PG, Bodine DM. 2008. Failure of terminal erythroid differentiation in EKLF-deficient mice is associated with cell cycle perturbation and reduced expression of E2F2. Mol Cell Biol 28: 7394-7401.

Rooke HM, Orkin SH. 2006. Phosphorylation of Gatal at serine residues 72,142 , and 310 is not essential for hematopoiesis in vivo. Blood 107: 3527-3530. 
Rylski M, Welch JJ, Chen YY, Letting DL, Diehl JA, Chodosh LA, Blobel GA, Weiss MJ. 2003. GATA-1-mediated proliferation arrest during erythroid maturation. Mol Cell Biol 23: 50315042.

Sankaran VG, Ghazvinian R, Do R, Thiru P, Vergilio JA, Beggs AH, Sieff CA, Orkin SH, Nathan DG, Lander ES, et al. 2012. Exome sequencing identifies GATA1 mutations resulting in Diamond-Blackfan anemia. J Clin Invest 122: 2439-2443.

Siatecka M, Sahr KE, Andersen SG, Mezei M, Bieker JJ, Peters LL. 2010. Severe anemia in the Nan mutant mouse caused by sequence-selective disruption of erythroid Kruppel-like factor. Proc Natl Acad Sci 107: 15151-15156.

Staerk J, Kallin A, Demoulin JB, Vainchenker W, Constantinescu SN. 2005. JAK1 and Tyk2 activation by the homologous polycythemia vera JAK2 V617F mutation: cross-talk with IGF1 receptor. J Biol Chem 280: 41893-41899.

Tallack MR, Perkins AC. 2010. KLF1 directly coordinates almost all aspects of terminal erythroid differentiation. IUBMB Life 62: 886-890.

Tallack MR, Keys JR, Humbert PO, Perkins AC. 2009. EKLF/ KLF1 controls cell cycle entry via direct regulation of E2f2. J Biol Chem 284: 20966-20974.

Teng R, Gavrilova O, Suzuki N, Chanturiya T, Schimel D, Hugendubler L, Mammen S, Yver DR, Cushman SW, Mueller E, et al. 2011. Disrupted erythropoietin signalling promotes obesity and alters hypothalamus proopiomelanocortin production. Nat Commun 2: 520.

Tsiftsoglou AS, Vizirianakis IS, Strouboulis J. 2009. Erythropoiesis: model systems, molecular regulators, and developmental programs. IUBMB Life 61: 800-830.
Vainchenker W, Constantinescu SN. 2005. A unique activating mutation in JAK2 (V617F) is at the origin of polycythemia vera and allows a new classification of myeloproliferative diseases. Hematology Am Soc Hematol Educ Program 195-200.

Wechsler J, Greene M, McDevitt MA, Anastasi J, Karp JE, Le Beau MM, Crispino JD. 2002. Acquired mutations in GATA1 in the megakaryoblastic leukemia of Down syndrome. Nat Genet 32: $148-152$.

Weiss MJ, Yu C, Orkin SH. 1997. Erythroid-cell-specific properties of transcription factor GATA-1 revealed by phenotypic rescue of a gene-targeted cell line. Mol Cell Biol 17: 16421651.

Whyatt DJ, Karis A, Harkes IC, Verkerk A, Gillemans N, Elefanty AG, Vairo G, Ploemacher R, Grosveld F, Philipsen S. 1997. The level of the tissue-specific factor GATA-1 affects the cell-cycle machinery. Genes Funct 1: 11-24.

Wong JV, Dong P, Nevins JR, Mathey-Prevot B, You L. 2011. Network calisthenics: control of E2F dynamics in cell cycle entry. Cell Cycle 10: 3086-3094.

Yin S, Girnita A, Stromberg T, Khan Z, Andersson S, Zheng H, Ericsson C, Axelson M, Nister M, Larsson O, et al. 2010. Targeting the insulin-like growth factor-1 receptor by picropodophyllin as a treatment option for glioblastoma. Neuro Oncol 12: 19-27.

Zhao W, Kitidis C, Fleming MD, Lodish HF, Ghaffari S. 2006. Erythropoietin stimulates phosphorylation and activation of GATA-1 via the PI3-kinase/AKT signaling pathway. Blood 107: 907-915. 


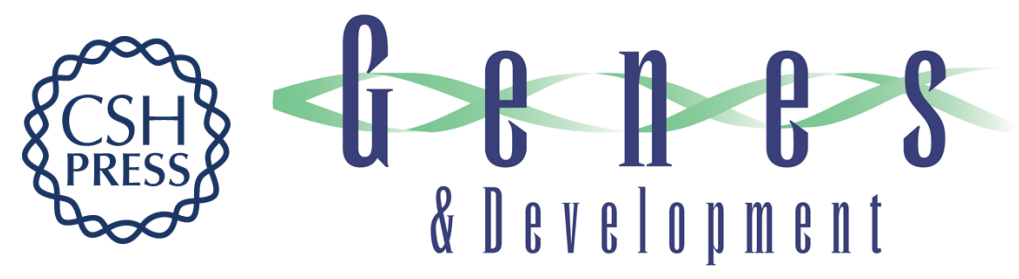

\section{Erythropoietin and IGF-1 signaling synchronize cell proliferation and maturation during erythropoiesis}

Zahra Kadri, Carine Lefevre, Olivier Goupille, et al.

Genes Dev. 2015, 29:

Access the most recent version at doi:10.1101/gad.267633.115

Supplemental
Material http://genesdev.cshlp.org/content/suppl/2015/12/17/29.24.2603.DC1

References This article cites 54 articles, 34 of which can be accessed free at:

http://genesdev.cshlp.org/content/29/24/2603.full.html\#ref-list-1

Creative This article is distributed exclusively by Cold Spring Harbor Laboratory Press for the first Commons

License

Email Alerting

Service six months after the full-issue publication date (see

http://genesdev.cshlp.org/site/misc/terms.xhtml). After six months, it is available under a Creative Commons License (Attribution-NonCommercial 4.0 International), as described at http://creativecommons.org/licenses/by-nc/4.0/.

Receive free email alerts when new articles cite this article - sign up in the box at the top right corner of the article or click here.

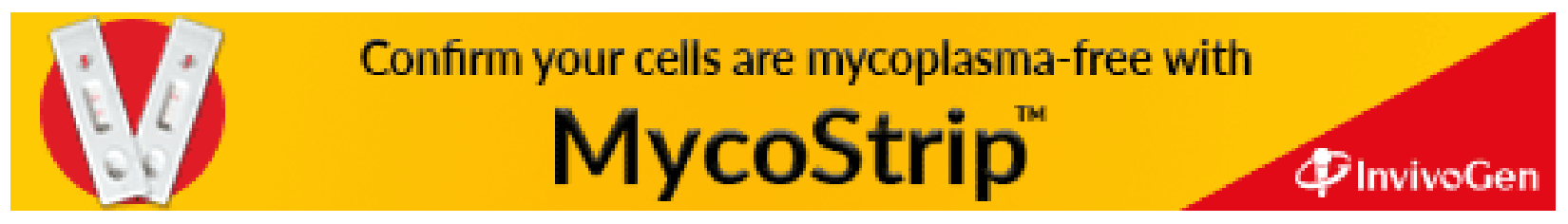

